\title{
The Myth of Air Purifier in Mitigating the Transmission Risk of SARS-CoV-2 Virus
}

\section{Aerosol and Air Quality Research}

Special Issue:

Special Issue on Air Quality in a Changed World: Regional, Ambient, and Indoor Air Concentrations from the COVID to Post-COVID Era (III)

\section{OPEN ACCESS}

Received: August 31, 2021 Revised: January 10, 2022 Accepted: January 18, 2022

\section{${ }^{*}$ Corresponding Authors: \\ Lip Huat Saw \\ sawlh@utar.edu.my \\ Mohd Shahrul Mohd Nadzir \\ shahrulnadzir@ukm.edu.my}

\section{Publisher:}

Taiwan Association for Aerosol Research

ISSN: $1680-8584$ print

ISSN: 2071-1409 online

(c) Copyright: The Author(s). This is an open access article distributed under the terms of the Creative Commons Attribution License (CC BY 4.0), which permits unrestricted use, distribution, and reproduction in any medium, provided the original author and source are cited.

\section{Lip Huat Saw ${ }^{1 *}$, Bey Fen Leo ${ }^{2}$, Chin Yik Lin ${ }^{3}$, Norfilza Mohd Mokhtar ${ }^{4}$, Sawal Hamid Md Ali ${ }^{5}$, Mohd Shahrul Mohd Nadzir ${ }^{6 *}$}

${ }^{1}$ Lee Kong Chian, Faculty of Engineering and Science, Universiti Tunku Abdul Rahman, Kajang, 43000, Selangor, Malaysia

2 Department of Molecular Medicine, Faculty of Medicine, Universiti Malaya, 50603, Kuala Lumpur Malaysia

${ }^{3}$ Department of Geology, Faculty of Science, Universiti Malaya, 50603, Kuala Lumpur, Malaysia

${ }^{4}$ Physiology Department, Faculty of Medicine, Universiti Kebangsaan Malaysia, Cheras, Kuala Lumpur 56000, Malaysia

${ }^{5}$ Department of Electrical, Electronic and Systems Engineering, Faculty of Engineering and Built Environment, Universiti Kebangsaan Malaysia, Bangi 43600, Selangor, Malaysia

${ }^{6}$ Department of Earth Sciences and Environment, Faculty of Science and Technology, Universiti Kebangsaan Malaysia, Bangi, 43600, Selangor, Malaysia

\section{ABSTRACT}

Severe acute respiratory syndrome coronavirus 2 (SARS-CoV-2) is a highly infectious disease that emerged in December of 2019, threatening human health and leading to global public health crises. Airborne transmission via droplets and aerosol has been recently recognized as one of the infection modes for the SARS-CoV-2 virus. Hospitals have deployed/incorporated indoor air purifiers with the hope to minimize the transmission risk of SARS-CoV-2 virus. Nevertheless, the effectiveness of the indoor air purifier in reducing the transmission risk remained unknown. This study uses computational fluid dynamics to model the dispersion of the aerosol particles exhaled from the patient under the influence of an air conditioner, exhaust fans and air purifier. The numerical model showed that airflow from the diffusers, exhaust fans and placement of the air purifier significantly influenced the dispersion pattern of the aerosol particles in the common ward. Multiple air purifiers placed at 1 meter above the floor and next to a patient can increase the total efficiency from 37.14 to $59.91 \%$ for weak exhalation and from $36.44 \%$ to $48.81 \%$ for medium exhalation. No aerosol particles flew out from the door for weak and medium exhalation when multiple air purifiers were deployed in the common ward. Location and matching the clean air delivery rate with the size of the room are the important factors that affect the performance of the air purifier.

Keywords: COVID-19, Airborne, Virus transmission, Air purifier, Computational fluid dynamic

\section{INTRODUCTION}

Severe acute respiratory syndrome coronavirus 2 (SARS-CoV-2) is a pathogenic and airbornebased highly transmissible virus that threatens human health and public safety globally (Sharma et al., 2020). As of $8^{\text {th }}$ May 2021, SARS CoV-2 has infected more than 156 million people and caused over 3.26 million deaths worldwide (Dong et al., 2020). Among all the major transmission routes, air-borne transmission of SARS-CoV-2 containing aerosol particles is likely to cause the rapid spreading of the virus and Delta and Omicron variants are not excluded from the airborne transmission route (Tellier et al., 2020; Lee, 2021).

Scientific studies have shown that an infected person expels virus-containing droplets (or bioaerosols) ranging from 5 to $20 \mu \mathrm{m}$ in size through speaking, sneezing or coughing (Li et al., 2020; 
Liu and Ning, 2020). The virus-containing respiratory droplets may enter human lungs through inhalation of contaminated air, affecting all components of the respiratory system. These droplets have a higher tendency to remain suspended in the air for a short period. van Doremalen et al. (2020) claimed that the SARS-CoV-2 was able to stay viable in aerosols for hours and on surfaces up to days. It was reported that the transmission rate of the virus is faster and more effective in crowded, enclosed rooms such as restaurants, schools, meeting rooms, hospital wards, and offices with poor ventilation and low humidity level less than 40\% RH (Jones et al., 2020; Ahlawat et al., 2020). One of the famous superspreading cases was reported in the poor ventilated Diamond Princess cruise ship (Almilaji, 2021). Thus, suitable measures are urgently needed to control the rapid transmission of the SARS-CoV-2 containing droplets, especially in poorly ventilated areas. These measures are particularly crucial to safeguard healthcare workers who are in direct contact with Covid-19 infected patients in a confined space (Chia et al., 2020).

Proper ventilation equipped with good air filtration systems has proved to reduce the viral load or particles in the indoor hospital ward environment, decreasing the probability of infections among health care workers (Zhao et al., 2020). A study has claimed that SARS-CoV-2 is widely distributed in the air with a transmission distance of as much as four meters in hospital wards (Liu and Ning, 2020). On the other hand, Gorbunov (2020) reported that the aerosol particles generated by coughing and sneezing may travel as far as over $30 \mathrm{~m}$ under certain atmospheric conditions. To effectively control the airborne transmission of the virus in hospitals, WHO has recommended healthcare premises be equipped with proper ventilation systems that give at least $288 \mathrm{~m}^{3} \mathrm{~h}^{-1}$ ventilation rate per person (WHO, 2009). Besides, wearing a tight fit mask is effective in blocking virus particles emitted from the patient (Riediker and Monn, 2021). Unfortunately, most healthcare premises were not equipped with the ventilation system recommended by the WHO.

A portable indoor air purifier is a modern technology to reduce harmful pollutants in the indoor environment and provide clean air to the surrounding (Cooper et al., 2021; Liu et al., 2021). A portable indoor air purifier equipped with a high-efficiency particulate air (HEPA) filter is the primary filtration mechanism to filter the $\mathrm{PM}_{2.5}$ and other harmful pollutants to provide clean air. Though, the effectiveness of the air purifier is heavily dependent on the various conditions such as the presence of window(s) for natural ventilation, the number of operating hours, the capacity of the air purifier against the size of the room, air conditioner ventilation systems, infiltration rates and location of the air purifier (Shaughnessy and Sextro, 2006; Novoselac and Siegel, 2009). In theory, when the air in an enclosed room is drawn continuously by the filter, the amount of viruscontaining particles in the room will be significantly reduced. It has been recently demonstrated that the usage of HEPA grade purifiers with a high exchange rate can significantly reduce the aerosol load in classrooms with no ventilation systems (Curtius et al., 2020). The authors estimated that the average inhaled dose from a highly contagious person is reduced by a factor of six when using an air purifier with an air exchange rate of $5.7 \mathrm{~h}^{-1}$ in a closed room.

Numerous studies studied the airborne transmission of droplets using computational fluid dynamic (CFD) modelling to analyze the risk of airborne transmission (Vuorinen et al., 2020; Bhattacharyya et al., 2020; Ren et al., 2021; Borro et al., 2021). Vuorinen et al. (2020) used CFD to predict the transmission of SARS-CoV-2 virus particles through aerosol and droplets in the shopping complex under influence of ventilation. On the other hand, the dispersion of the SARS-CoV-2 virus in the hospital setting is being investigated by Bhattacharyya et al. (2020), Ren et al. (2021) and Borro et al. (2021). It was found out that ventilation condition is one of the key factors affecting the transmission and dispersion of the SARS-CoV-2 virus. Besides, the effectiveness of air purifier systems has also been identified using modelling methods. For example, the simulation-based study of the use of portable air purification in the dental environment was investigated by Neha and Bojan (2020), showing the peak particle number was ten times lower in a room without an air purifier or a room with an open window, reducing the infection risks significantly (Raghava and Vidovic, 2020). Besides, a smart and compact SARS-CoV-2 air purifier was designed to create isolated pockets of air for separate groups around tables to prevent contaminated air from spreading between tables in an indoor environment (i.e., office, restaurant, and school (Bergam et al., 2020)). Furthermore, the efficiency of the air purifier system in a classroom under realistic conditions (e.g., including thermally driven flow effects) was studied numerically and experimentally by Burgmann and Janoske (2021). The authors demonstrated that the position of the air purifier and the outflow characteristic in the room may influence the efficiency of the system considerably. Despite several 
reports claiming that portable air purifiers can reduce the $\mathrm{PM}_{2.5}$ in the spaces (McNamara et al., 2017; Shao et al., 2017) and the SARS-CoV-2 at home or hospital wards (Elias and Bar-Yam, 2020), the effectiveness of the indoor air purifier in reducing airborne transmission of the virus remains enigmatic.

Herein, this paper investigates the effectiveness of the indoor air purifier in controlling SARSCoV-2 virus transmission at a common ward of COVID-19 hospital in Kuala Lumpur, Malaysia. The common ward was normally used to house mild types of infected patients. The existing ventilation condition and placement of the indoor air purifier in the common ward are modelled accordingly in the computational fluid dynamics study. The impact of the air conditioner diffuser, exhaled activities and indoor air purifier were investigated through Lagrangian particle tracking in the computational fluid dynamic simulations. The distribution analysis of the trapped and escaped particles from the common ward was used to predict the effectiveness of the air purifier on the mitigation of the SARS-CoV-2 virus transmission for the existing settings. Lastly, a new arrangement of multiple air purifiers at floor level and 1 meter above floor level are investigated to determine the optimum placement of the air purifier to improve the efficiency and reduce the dispersion of the exhaled particles in the patient ward. This paper is organized into several sections as follows: the numerical modeling and air sampling of the common ward are explained in the following section (section two). Section three describes the transport phenomenon of the particle under the influence of various exhalation flow rates, the cooling airflow from the air-conditioner diffuser and different arrangements of the air purifiers. The computational fluid dynamic analysis results were compared with previous experimental work on the air sampler analysis using Reverse Transcription Quantitative Real-Time Polymerase Chain Reaction (RT-qPCR) of the filter sample. Lastly, the conclusion of the current findings is placed in the last section.

\section{MODELING OF THE COMMON WARD FOR SARS-COV-2 MILD PATIENT}

\subsection{Common Ward Model and Indoor Air Quality Monitoring and Sampling}

Air sampling and monitoring of the common ward were conducted in a teaching hospital namely Hospital Canselor Tuanku Muhriz (HCTM) of Universiti Kebangsaan Malaysia in Kuala Lumpur, Malaysia for 48 hours from $4^{\text {th }}$ April to $13^{\text {th }}$ April 2020 to collect the air sample in the common ward. In-house air quality sensor AiRBOXSense (UKM Tech Sdn Bhd, Malaysia) was used to measure and monitor the condition of $\mathrm{PM}_{2.5}$ inside the common ward. The collected data is stored in the Thingspeaks (ioBridge, USA) cloud storage and analyzed with Matlab software. On the other hand, a low volume air sampler (MiniVol, AirMetrics, USA) was used to collect the air sample with a flow rate of 5 liters per minute. Quartz microfiber filter paper (Whatman) with pores size of $0.6 \mu \mathrm{m}$ to $0.8 \mu \mathrm{m}$ was used as particle retention. The details of the air sample post-process and RT-qPCR test were described in the previously published work ((Nor et al., 2021).

The CAD model of the common ward was created using the commercial CAD software Solidworks 2017. The dimension of the common ward is $17840 \mathrm{~mm}$ (length) $\times 7500 \mathrm{~mm}$ (width) $\times 2900 \mathrm{~mm}$ (height) that accommodates ten mild SARS-CoV-2 patients. The patients were placed next to both sides of the wall and the size of the bed is $2140 \mathrm{~mm}$ (length) $\times 1040 \mathrm{~mm}$ (width) $\times 760 \mathrm{~mm}$ (height). The patient lied in the middle of the bed assuming aerosol particles were produced from daily exhalation activities such as breathing and talking. The central air conditioner unit was installed in the common ward. There were eight diffusers and one outlet in the common ward. The calculated air change rate for the common ward was about $7 \mathrm{ACH}$ (Air change Per Hour) with the supply air temperature at $24^{\circ} \mathrm{C}$. Besides, there were two wall-mounted exhaust fans installed in the common ward too. Each of the wall-mounted exhaust fans exhausts $1235 \mathrm{CMH}$ of air from the common ward. In addition, one unit of the air purifier was placed in the ward to remove contaminants from the air and improve indoor air quality. The portable air purifier (Fanfill Air Purifier-AP510M) was equipped with HEPA filter and operated at $700 \mathrm{CMH}$ of air inflow and the clean air delivery rate (CADR) is $434 \mathrm{CMH}$ with a $\mathrm{PM}_{2.5}$ removal efficiency of $99 \%$ for a room of $50 \mathrm{~m}^{2}$. The dimension of the air purifier is about $500 \mathrm{~mm}$ (length) $\times 340$ (width) $\times 658 \mathrm{~mm}$ (height). The air intake for the air purifier was located at the lower part (both sides and bottom) and the outlet of the air purifier was located at the upper part (top and both sides) of the machine. The air purifier was located 


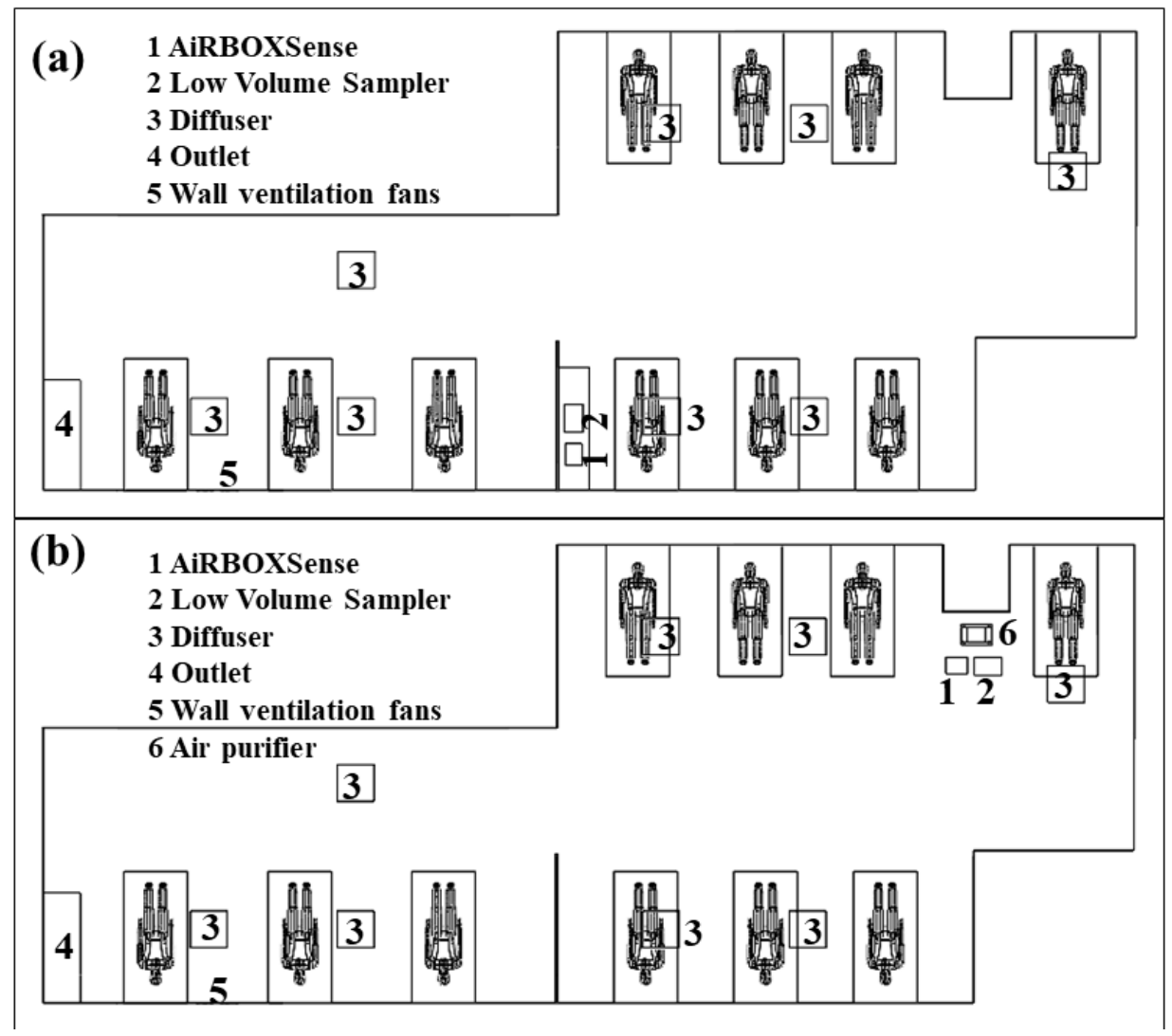

Fig. 1. (a) Common ward with air sampling and monitoring sensors only. (b). Common ward with air sampling, monitoring sensors and indoor air purifier.

near the exit of the common room and operated for 24 hours. The CAD model of the common ward and the location of the air quality monitoring sensors and indoor air purifier are illustrated in Fig. 1.

\subsection{Numerical Procedures}

To predict the effectiveness of the indoor air purifier in preventing the dispersion of the SARSCoV-2, a commercial computational fluid dynamic package ANSYS-CFX was used to characterize the dispersion of the SARS-CoV-2 virus which is difficult to observe in the experimental visualization. In this study, the following assumptions are used to model the dispersion of the aerosol particles from the patient in the hospital and the effect of the air purifier.

1. Unsteady exhalation particle tracking.

2. The air supply by the inlet of the central air conditioning system is constant throughout the study.

3. There is no heat source in the air domain and the heat is dissipated from the patient body.

4. Since the modeled particle is small. There is no evaporation of the aerosol particles expelled from the patient.

5. The influence of particles on airflow is neglected.

6. The particles are in an ideal sphere shape.

7. Particles are completely filtered and no particles escape or discharge from the air purifier

In this study, the air is treated as continuous fluid while aerosol particles exhaled from the patient are treated as particle transport fluid. The Lagrangian particle tracking model is used to trace the dispersion of the SARS-CoV-2 virus particles in the CFD study. The conservation of mass is written as in Eq. (1) (Ashgriz and Mostaghimi, 2002; Marzec et al., 2021; Saw et al., 2018).

$$
\frac{\partial \rho}{\partial t}+\nabla \cdot(\rho \mathbf{u})=0
$$


where $\mathbf{u}$ is the velocity vector, $\rho$ is the density and $t$ is the time.

The conservation of momentum equation is written as in Eq. (2) (Ashgriz and Mostaghimi, 2002; Marzec et al., 2021; Saw et al., 2018).

$$
\frac{\partial(\rho \mathbf{u})}{\partial t}+\nabla \cdot(\rho \mathbf{u u})=-\nabla p+\rho g+\nabla \cdot \tau+\nabla \cdot \tau^{R}
$$

where $p$ is the static pressure, $\mathrm{g}$ is the gravitational acceleration, $\tau$ is the shear stress tensor due to molecular viscosity and $\tau^{R}$ is the Reynolds stress tensor, which describes the stress caused by turbulence flow.

The energy balanced equation is defined by Eq. (3) (Ashgriz and Mostaghimi, 2002; Marzec et al., 2021; Saw et al., 2018):

$$
\frac{\partial(\rho E)}{\partial t}+\nabla \cdot(\mathbf{u}(\rho \mathbf{E}+\mathbf{p}))=\nabla \cdot\left(k_{e f f} \nabla T\right)
$$

where $E$ is total energy and $k_{\text {eff }}$ is the effective thermal conductivity which is the sum of thermal conductivity and turbulent thermal conductivity.

The standard two-equation $k-\omega$ SST turbulence model with automatic wall function was used to predict the dispersion of the SARS-CoV-2 virus particles in the common ward. The two-equation k- $\omega$ SST turbulence model is a proven stable and numerically robust turbulence model that compromises accuracy and robustness. The robustness of the two-equation k- $\omega$ SST turbulence model is validated by various researchers (Huang et al., 1997; Sparrow et al., 2009; Menter et al., 2003; Lee et al., 2013). The two-equation k- $\omega$ SST turbulence model is developed to overcome the shortage of the $k-\omega$ and BSL k- $\omega$ model. Besides, the model also offered the advantages in the near-wall treatment for low Reynolds number computations and better prediction of the turbulent shear stress with modification of the eddy viscosity term.

In an indoor environment, air conditioner and indoor air purifier play a major role in affecting the dispersion of the droplet and aerosol. A three-dimensional steady-state two-phase flow CFD simulation with Lagrangian tracking was used to investigate the dispersion of the SARS-CoV-2 virus particles in the common ward equipped with an air purifier and without air purifier. Humans exhale various sizes of particles, larger particle size $(>1 \mu \mathrm{m})$ is normally detected during coughing and sneezing (Tang et al., 2013; Chao et al., 2009; Fabian et al., 2011; Yang et al., 2007) while smaller particles are detected during tidal breathing (Papineni and Rosenthal, 1997; Saw et al., 2021; Edwards et al., 2004). Most of the particles exhaled during tidal breathing are less than $1 \mu \mathrm{m}$. Smaller particles stay in the air for a prolonged period and can travel more than $6 \mathrm{~m}$ under the influence of airflow (Vuorinen et al., 2020; Bourouiba, 2020). It was found that SARS-CoV-2 virus particles in the range of $65 \mathrm{~nm}$ to $125 \mathrm{~nm}$ can inhabit the droplet or aerosol during coughing, sneezing and tidal breathing (Kim et al., 2020; Shereen et al., 2020). During the SARS-CoV-2 pandemic outbreak, air purifiers were deployed in normal wards to provide clean air and at the same time to reduce the risk of infection. To investigate the effectiveness of the air purifier, 3000 particles consisting of 10 different sizes were assigned to the patient's mouth to represent aerosol particles exhaled from the patient. The distribution of the particle sizes used in the simulation was $0.07 \mu \mathrm{m}, 0.1 \mu \mathrm{m}, 0.3 \mu \mathrm{m}, 0.5 \mu \mathrm{m}, 0.8 \mu \mathrm{m}$, $1.0 \mu \mathrm{m}, 2.0 \mu \mathrm{m}, 5.0 \mu \mathrm{m}, 8.0 \mu \mathrm{m}$ and $10 \mu \mathrm{m}$. The particle size was selected to give more resolution for fine particles to validate the previous experimental results. Since the common ward was used to house mild patients, only weak and medium expiration are considered. Weak expiration represents breathing while medium expiration represents talking (Xie et al., 2009; Kwon et al., 2012). Two scenarios were studied in this work, one is the common ward equipped with the air purifier while another is without the air purifier. In total, four scenarios were analyzed for the common ward.

ANSYS meshing 19.0 was used to discretize the common ward CAD model for CFD analysis. Inflation layers were created to provide a more accurate resolution of the boundary layer. Fig. 2 shows the generated meshed model of the common ward. The cooling air supplied by the central air conditioner unit is assumed to be an ideal gas. The diffusers of the air conditioner were assigned with mass flow boundary conditions with a volume flow rate of $255 \mathrm{CMH}$, medium turbulence intensity of $5 \%$ and temperature of $24^{\circ} \mathrm{C}$. Opening and pressure boundary condition was assigned 
for the air conditioner outlet. On the other hand, a mass flow outlet was assigned for the wallmounted exhaust fan with a volume flow rate of $1235 \mathrm{CMH}$ per fan. The air purifier has triple airway release and intake. The intakes of the air purifier were assigned with the mass flow boundary conditions at a volume flow rate of $233.33 \mathrm{CMH}$ per intake, medium turbulence intensity of $5 \%$ and temperature of $24^{\circ} \mathrm{C}$. On the other hand, the airway releases from the air purifier were assigned with mass flow inlet conditions at a volume flow rate of $144.67 \mathrm{CMH}$ per airway release, medium turbulence intensity of $5 \%$ and temperature of $24^{\circ} \mathrm{C}$. Besides, the door of the common ward was assigned to the opening and pressure boundary condition. Next, the non-slip wall and adiabatic wall boundary conditions were assigned for the bed and wall of the common ward. Water properties were assumed for the aerosol particles exhaled from the patient's mouth. The patient's mouths were assigned to a velocity boundary condition of $1.3 \mathrm{~m} \mathrm{~s}^{-1}$ for weak expiration and $4.5 \mathrm{~m} \mathrm{~s}^{-1}$ for medium expiration, medium turbulence intensity of $5 \%$ and temperature of $37.8^{\circ} \mathrm{C}$ (Xie et al., 2009; Kwon et al., 2012). The particle mass flow rate for weak expiration is $0.01 \mathrm{~g} \mathrm{~s}^{-1}$, and medium expiration is $0.01 \mathrm{~g} \mathrm{~s}^{-1}$ (Xie et al., 2009; Kwon et al., 2012). Uniform heat flux generation of $23 \mathrm{~W} \mathrm{~m}^{-2}$ and body temperature of $37.8^{\circ} \mathrm{C}$ was assigned for the patient body (Zhu et al., 2006). The common ward computational domain was initialized with 1 atm pressure. A high-resolution advection scheme was used for all CFD simulation cases. Lastly, tight convergence criteria were applied for residuals of the continuity, momentum, and energy equations with the root mean square of the variable falling below $1 \times 10^{-6}$. The CFD modeling works were performed on the workstation equipped with Intel i7-6800K, 3.40 GHz processor and 112 GB RAM. The total computational time is about 73 hours. The boundary conditions' details of the computational model are illustrated in Figs. 2-4 and Table 1.

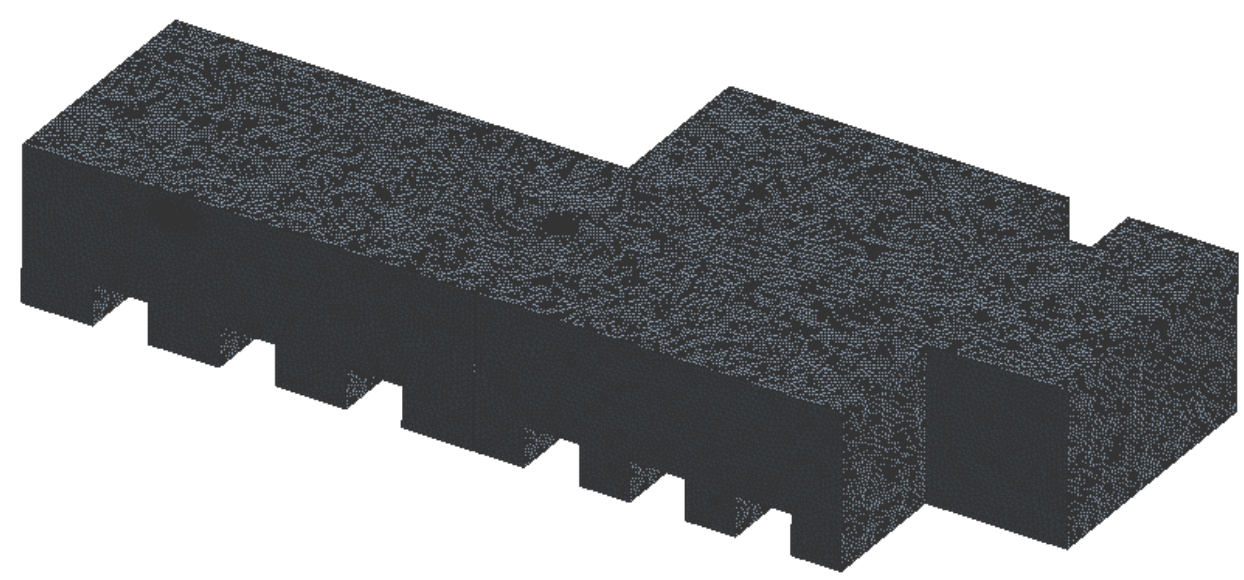

Fig. 2. Generated mesh of the common ward.

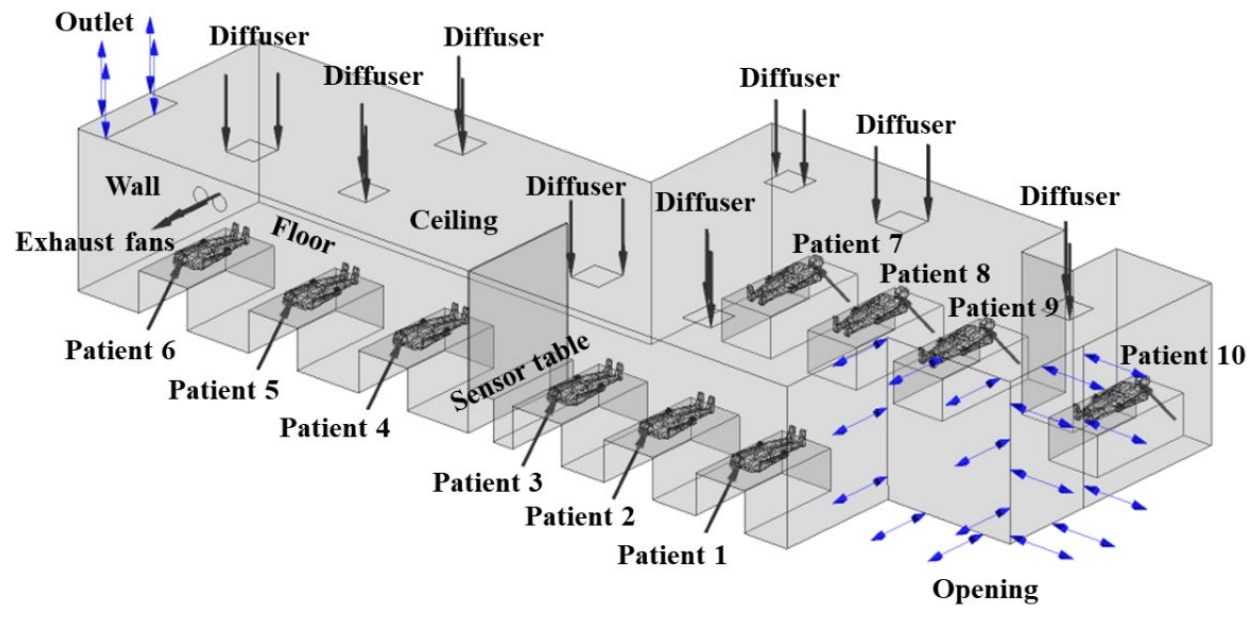

Fig. 3. Boundary conditions of the common ward without an air purifier. 


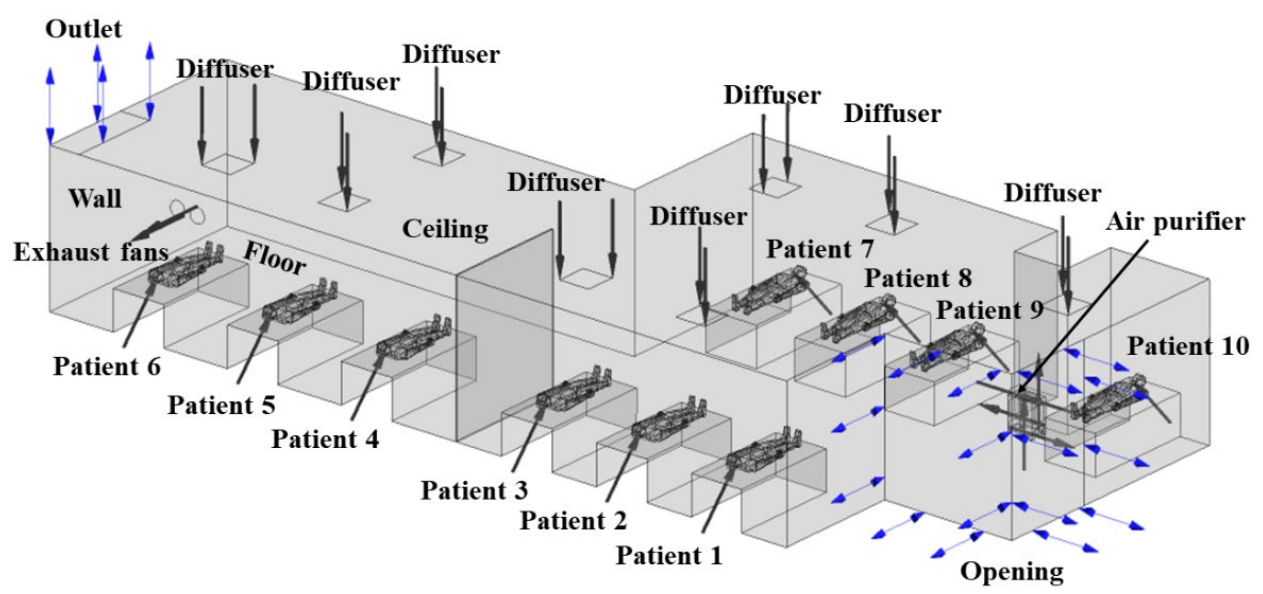

Fig. 4. Boundary conditions of the common ward with an air purifier.

Table 1. Boundary conditions details of the hospital common ward with mild SARS-CoV-2 patients in ANSYS CFX.

\begin{tabular}{|c|c|c|}
\hline Boundary name & Boundary details & \\
\hline \multirow[t]{6}{*}{ Fluid domain } & Temperature & $24^{\circ} \mathrm{C}$ \\
\hline & Patient body and bed & Non-slip wall \\
\hline & Heat generated on patient body & $23 \mathrm{~W} \mathrm{~m}^{-2}$ \\
\hline & Patient body temperature & $37.8^{\circ} \mathrm{C}$ \\
\hline & Common ward wall & Non-slip wall \\
\hline & Common ward heat transfer & Adiabatic \\
\hline \multirow[t]{3}{*}{ Air conditioning diffuser } & Temperature & $24^{\circ} \mathrm{C}$ \\
\hline & Turbulence intensity & $5 \%$ \\
\hline & Flow rate per diffuser & $255 \mathrm{CMH}$ \\
\hline Air conditioning outlet & Opening pressure & $0 \mathrm{~Pa}$ \\
\hline Wall exhaust fan & Flow rate & $1235 \mathrm{CMH}$ \\
\hline \multirow[t]{2}{*}{ Air purifier } & Clean air delivery rate & $434 \mathrm{CMH}$ \\
\hline & Air suction rate & $700 \mathrm{CMH}$ \\
\hline \multicolumn{3}{|l|}{ Weak exhalation scenario } \\
\hline \multirow[t]{3}{*}{ Patient mouth } & Saliva mass flow rate & $0.01 \mathrm{~g} \mathrm{~s}^{-1}$ \\
\hline & Average velocity & $1.3 \mathrm{~m} \mathrm{~s}^{-1}$ \\
\hline & Temperature & $37.8^{\circ} \mathrm{C}$ \\
\hline \multicolumn{3}{|c|}{ Medium exhalation scenario } \\
\hline \multirow[t]{3}{*}{ Patient mouth } & Saliva mass flow rate & $0.05 \mathrm{~g} \mathrm{~s}^{-1}$ \\
\hline & Average velocity & $4.5 \mathrm{~m} \mathrm{~s}^{-1}$ \\
\hline & Temperature & $37.8^{\circ} \mathrm{C}$ \\
\hline Particle size & Distribution & $\begin{array}{l}0.07 \mu \mathrm{m}, 0.1 \mu \mathrm{m}, 0.3 \mu \mathrm{m}, 0.5 \mu \mathrm{m}, 0.8 \mu \mathrm{m}, \\
1.0 \mu \mathrm{m}, 2.0 \mu \mathrm{m}, 5.0 \mu \mathrm{m}, 8.0 \mu \mathrm{m} \text { and } 10 \mu \mathrm{m}\end{array}$ \\
\hline
\end{tabular}

\subsection{Grid Independence Studies}

Refinement of the grid is important to ensure the results are accurate and independent of the mesh size. Hence, systematic grid independent studies were conducted to ensure the computational domain and the results are not affected by further refinement of the grid. The influence of the grid is evaluated in terms of velocity and temperature, and the relative error is kept less than $1 \%$. The results of the grid independence analysis are presented in Table 2. As shown in Table 2, four sets of grid independent tests with mesh-1 (coarse) 3740328, mesh-2 (medium) 4911226, mesh-3 (fine) 8161214 and mesh-4 (finest) 16004274 are conducted. The relative error in the computed averaged velocity for mesh-2 to mesh-1, mesh-3 to mesh-2, and mesh-4 to mesh-3 is about $3.08 \%, 0.88 \%$ and $0.71 \%$, respectively. On the other hand, the relative error in the computed averaged temperature for mesh- 2 to mesh- 1 , mesh- 3 to mesh-2, and mesh- 4 to mesh mesh- 3 is 
Table 2. Grid independence analysis of the common ward.

\begin{tabular}{lllll}
\hline & Mesh-1 & Mesh-2 & Mesh-3 & Mesh-4 \\
\hline Mesh Number & 3740328 & 4911226 & 8161214 & 16004274 \\
Velocity, $\mathrm{m} \mathrm{s}^{-1}$ & 0.0552 & 0.0569 & 0.0564 & 0.0598 \\
Relative error, \% & - & 3.08 & 0.88 & 0.71 \\
Temperature, ${ }^{\circ} \mathrm{C}$ & 298.25 & 298.08 & 298.05 & 298.07 \\
Relative error, \% & - & 0.057 & 0.010 & 0.0067 \\
\hline
\end{tabular}

about $0.057 \%, 0.010 \%$ and $0.0067 \%$, respectively. This shows that mesh- 4 with a total mesh size of 16004274 is sufficient to model the airflow in the given scenario of interest.

\subsection{Proposed New Arrangement of the Air Purifier}

The efficiency of the air purifier depends greatly on the location, design of the air purifier, flow rate of the conditioned air supply and location of the diffuser and outlet. The distribution of the airflow is one of the important factors that affect the dispersion of the aerosol particles in the room (Saw et al., 2021). In this study, the efficiency of the air purifier was evaluated at different heights. The air purifier is placed on the floor and elevated 1 meter above the floor. Instead of one air purifier for a room, multiple air purifiers are used and placed between the patients to improve the filtration of the aerosol inside the room. The new arrangement of the air purifiers as shown in Fig. 5 is proposed for the common ward. However, no air purifier was placed between patient 5 and patient 6 . This is due to the proximity of two exhaust fans and one outlet of the air conditioner in that area which is sufficient to vent out the aerosol particles present in that region.

\section{(a)}

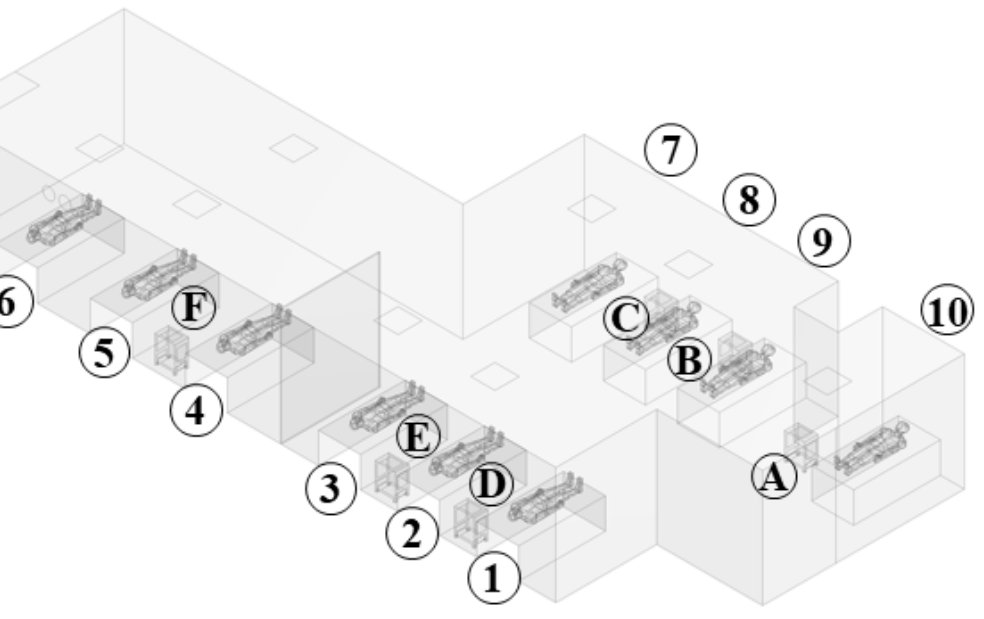

(b)

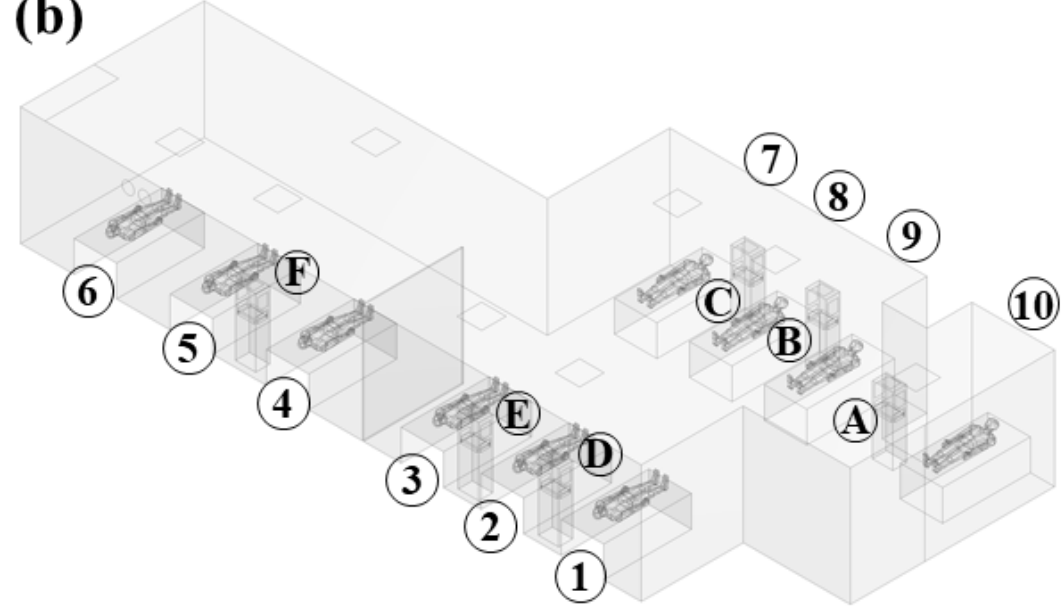

Fig. 5. Placing of the air purifier between the patient. (a) at floor level. (b) 1 meter above the floor. 


\section{RESULTS AND DISCUSSION}

\subsection{Common Ward Airflow Field}

There are seven air conditioner diffusers and a single air outlet in the common ward, which is a typical ducted type of air conditioner system. The velocity of the aerosol particles exit from the patient's mouth decreases rapidly. The average airflow velocity in the room at $1.5 \mathrm{~m}$ above the floor is approximately $0.042 \mathrm{~m} \mathrm{~s}^{-1}$, and the common ward is in a calm state.

The vector plot of the airflow velocity in the common ward at $1.5 \mathrm{~m}$ above the floor and the cross-sectional view of the velocity distribution vector plot of the patient with weak and medium exhalation is shown in Fig. 6 . The airflow velocity distribution is taken at the human breathing zone which is about $1.5 \mathrm{~m}$ from the ground. The figure suggests that the dispersion of the aerosol particles is affected by the airflow induced by the ventilation system.

Due to the uneven layout of the common ward (such as the location of the bed and air conditioning diffusers and outlet), the airflow pattern is not uniformly distributed. It is found that the velocity of the airflow is higher near the exhaust fans and below the air conditioner diffusers at the left portion of the room. This is due to the portion of the airflow exiting the common ward through the exhaust fans at the leftmost end. On the other hand, recirculation airflow was observed at the back end of the common ward near the middle partition. Compared to the scenario of weak exhalation, medium exhalation creates a strong interference with the airflow around the patient as shown in Figs. 6(b) and 6(c). The bed obstructs the cooling airflow and creates a weak vortex in the region around the legs of the patient.

The temperature distribution across the vertical plane placed on the patients laid on the bed is shown in Fig. 7. For the patient that is facing the air conditioner diffuser, the flow direction of the thermal plume is different as compared to the patient that is not directly facing the air conditioner diffuser. This effect is evident in Fig. 7(a) where the non-symmetrical distribution of the air-conditioning diffuser in the ward may affect the evolution of the thermal plumes. The fourth patient from the left shown in Fig. 7(a) has limited access to cooling air compared to others. Hence, no prominent thermal plume is observed.

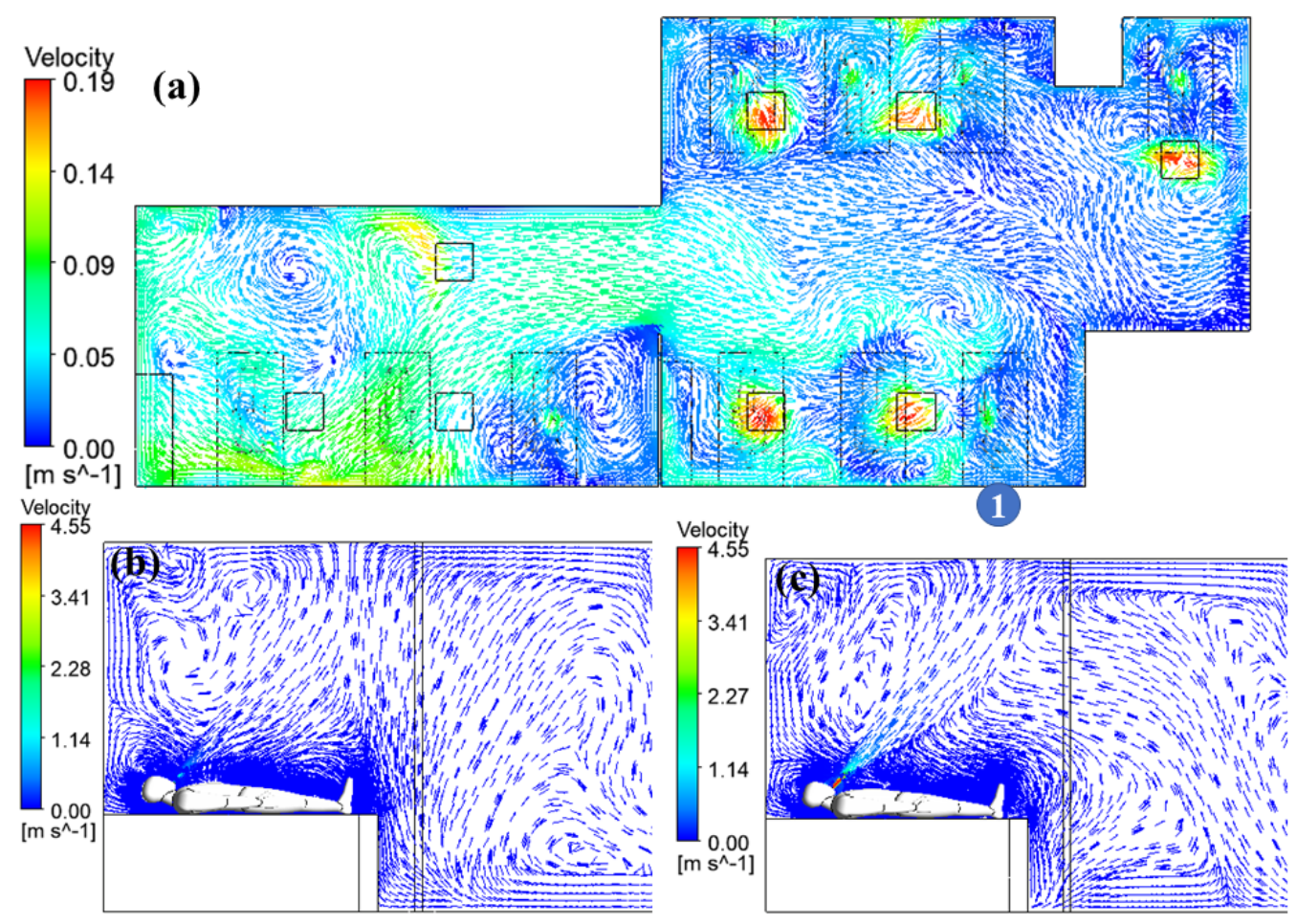

Fig. 6. (a) Airflow velocity distribution measured at $1.5 \mathrm{~m}$ above the ground. Cross-sectional views of the airflow velocity for patient 1 with (b) weak exhalation. (c) medium exhalation. 


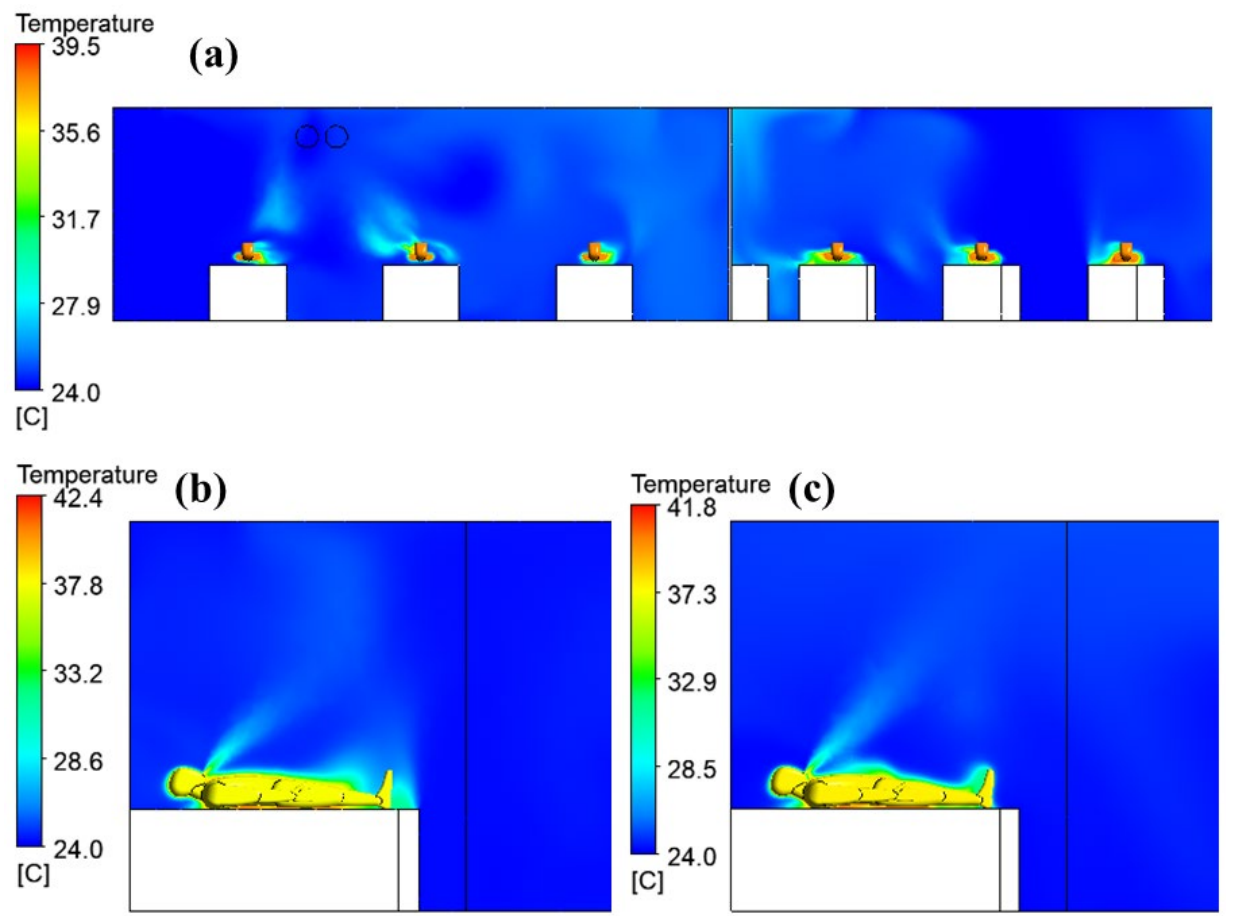

Fig. 7. (a) Front cross section-view of the patient with weak exhalation. (b) Middle cross sectionview of the patient with weak exhalation. (c) Middle cross section-view of the patient with medium exhalation.

For weak expiration, the warm temperature airflow from the patient travelled at a lower speed affected by the ventilation air. The warm expiration airflow is slightly deflected away by the ventilation air shown in Fig. 7(b). For a medium exhalation scenario, the warm temperature airflow from the patient's mouth travels at high speed to the surrounding air. Thus, the velocity of the exhaled warm airflow is less affected by the ventilation and travels a greater distance from the mouth with lower temperature compared to weak exhalation as shown in Fig. 7(c).

\subsection{Transport of Aerosol Particles}

Fig. 8 illustrates the dispersion of the aerosol particles of the patient in the common ward for weak and medium exhalation at $15 \mathrm{~min}$ with an interval of $5 \mathrm{~s}$. As soon as the agglomerate aerosol particles were expelled from the patient's mouth, the particles rose up and instantly disintegrated under the influence of the buoyancy force. The aerosol particles began to spread in the common ward under the influence of the airflow generated by the air conditioner diffuser, outlet and exhaust fans. The particles that disperse in the air may eventually adhere to the wall, floor or escape out the room through the exhaust fans, outlet and opening of the door. Most of the aerosol particles exhaled from the SARS-CoV-2 positive patient remained airborne and lingered in the air for a prolonged time. The effect of gravity is less significant for small particles than large droplets (Saw et al., 2021). The model also indicates that the particles exhaled from medium exhalation can travel further compared to the particles from weak exhalation. The aerosol particles exhaled from the patient directly faces the air conditioner diffuser exhibits a greater dispersion compared to the patient that is not directly located near to the air conditioner diffuser. These exhaled particles will likely be more concentrated in the vicinity of the patient.

Human thermal plume caused by the rise of the warm airflow by natural convection along the human body is one of the important factors that affect the dispersion of the aerosol particles other than ventilation (Sun et al., 2021; Vianello et al., 2019; Ansaripour et al., 2016; Melikov, 2015). Under a calm environment, the effect of the human thermal plume on the dispersion of aerosol particles is more apparent. In addition, the velocity of the thermal plumes is also affected by the posture of the human body and ambient temperature (Sun et al., 2021). Licina et al. (2014) shows that when the ambient temperature is reduced, there will be a $50 \%$ increase in the thermal 

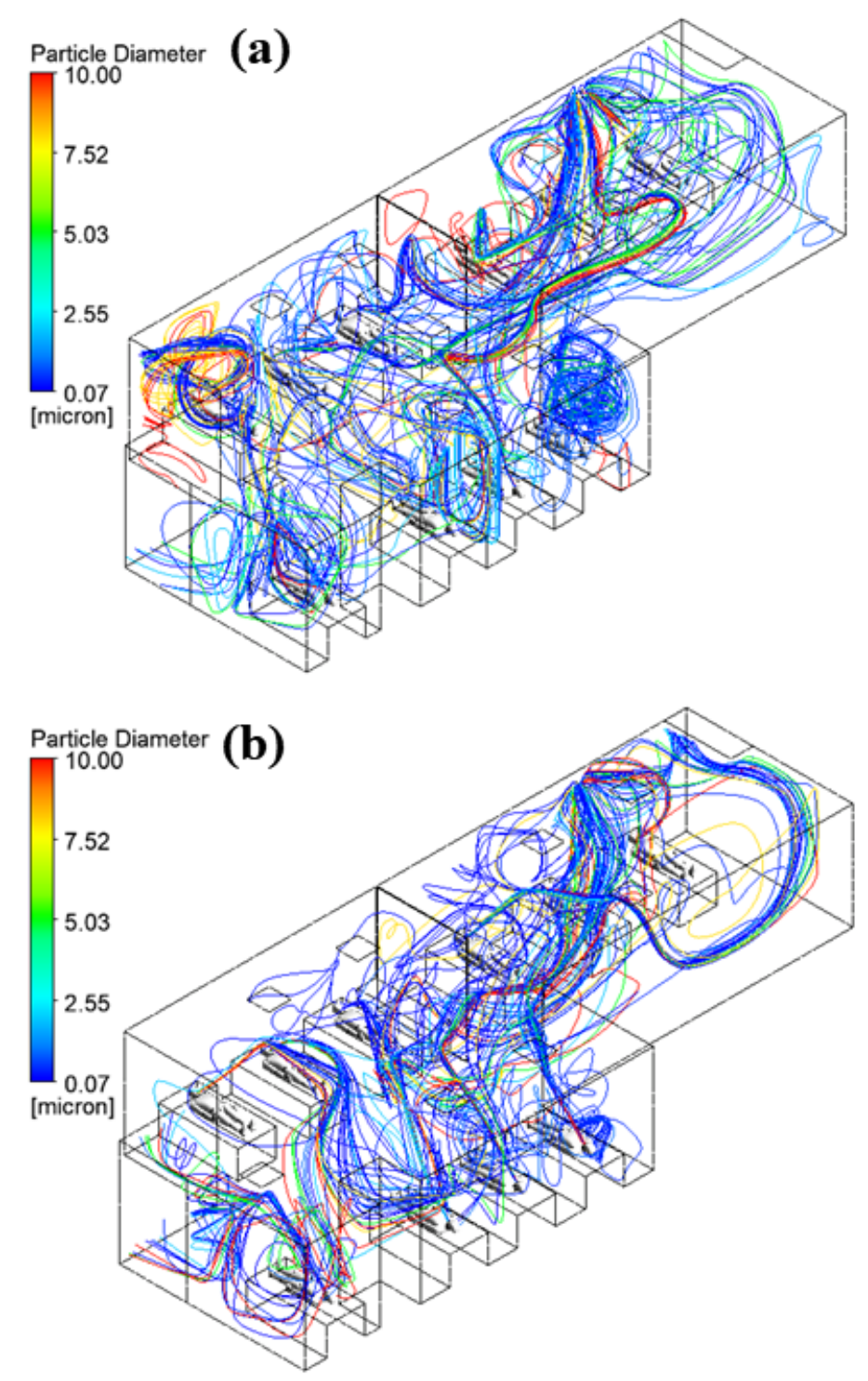

Fig. 8. Distribution of the exhaled particle (a) weak exhalation. (b) medium exhalation.

plumes velocity of the seated body are increased by $50 \%$. However, when the human body is at a lying position, the velocity of the thermal plume is lower than the sitting or standing body due to a shortage of convection accumulation (Feng et al., 2020). Hence, ventilation is a dominant factor in affecting the dispersion of droplets and aerosol particles.

As shown in Fig. 8(a) for weak exhalation, approximately $66 \%$ of the particle is concentrated at the front end compared to the back end of the common ward (which is about 34\%). This is because the exhaust fans and air outlet are located at the back end of the common ward, allowing effective ventilation of the indoor air. Furthermore, the distribution of the particles is measured at different heights of the common ward. At a height of $1.5 \mathrm{~m}$ to $2.0 \mathrm{~m}$ above the ground, about 9.94\% of the particles are found which is within the human breathing zone. It was found that about $61.27 \%$ of the particle is below $1.5 \mathrm{~m}$, whereas $28.79 \%$ of the particle is located above $2.0 \mathrm{~m}$. The total mass flow of the particles escaped through the door, exhaust fans and outlet are about $0.00464 \mathrm{~g} \mathrm{~s}^{-1}$ and $0.0860 \mathrm{~g} \mathrm{~s}^{-1}$, respectively. Approximately, $86.03 \%$ of the particles vented out from the room through the exhaust fans and about $9.33 \%$ of the aerosol remained in the common ward and did not escape through the door or exhaust fans. No aerosol particles are escaping through the outlet of the air conditioner, probably due to the strong suction of the exhaust fans.

The model shows that exhaled particles are penetrated a greater distance with a medium exhaled velocity of $4.5 \mathrm{~m} \mathrm{~s}^{-1}$. In this scenario, the distribution of the particles at the front end and 
back end of the common ward is comparable to the weak exhalation scenario. About $52.79 \%$ of the particle is concentrated at the front end of the common ward and $47.21 \%$ is found at the back end. In addition, the distribution of the particles in the breathing zone is about the same as the weak exhalation. About $56.02 \%$ of the particle is located below $1.5 \mathrm{~m}$, whereas $12.78 \%$ of the particle is within $1.5 \mathrm{~m}$ to $2.0 \mathrm{~m}$ and $31.19 \%$ of the particle is above $2.0 \mathrm{~m}$. The total mass flow of the particles escaped through the door and outlet which includes the exhaust fans is about $0.0524 \mathrm{~g} \mathrm{~s}^{-1}$ and $0.429 \mathrm{~g} \mathrm{~s}^{-1}$, respectively. Approximately, $85.73 \%$ of the particles vented out the room through the exhaust fans and about $3.80 \%$ of the aerosol remained in the common ward and do not escape through the door and exhaust fans. Similar to the weak exhalation scenario, no aerosol particles are escaping through the outlet of the air conditioner.

The above results show that the location of the air diffuser, outlet and exhaust fan greatly affect the transport phenomena of the particles. Aerosol particles have a time-varying tendency to diffuse toward the exhaust fan primarily due to the strong suction followed by through the door openings as a secondary route. This also implies that aerosol particles that contain SARS-CoV-2 virus could travel to unpredicted distances under the presence of air conditioners and mechanical ventilation systems. Thus, this may increase the risk of viral transmission in the room. Previous studies found that SARS-CoV-2 virus-laden aerosol particles can remain infectious for hours under room temperature (van Doremalen et al., 2020; Fears et al., 2020). Hence, it is believed that the region near the outlet of the air conditioner and exhaust fans possess a greater risk of infection. Strong downward airflow from the air conditioner diffuser is expected to deter the aerosol particles to ascend above $1.5 \mathrm{~m}$. The rise of the aerosol particles can only be promoted through the force circulation of airflow or turbulence after the sink (Yang et al., 2020). Subsequently, the particles may move forward, disperse and exit the ward through the door and outlet under the influence of the suction (negative pressure) from the exhaust fans. As a result, most of the particles concentrate at the front end of the common ward, thereby, increasing the risk of infection in the area. Besides, the number of particles present in the room mainly depends on the exhalation activities of the patient. It is predicted that more particles will be produced when the patient experiences more severe exhalation such as coughing or sneezing.

\subsection{Common Ward Airflow under the Influence of Air Purifier}

In this section, the effectiveness of portable air purifiers in reducing the transmission of SARSCoV-2 was investigated. The airflow field of the common ward installed with air purifiers is shown in Fig. 9. The air purifier is located at the right-hand side of the front end of the common ward. The portable air purifier has three airways to provide $434 \mathrm{CMH}$ of clean air to the surrounding. The two side airways distribute the clean air uninterruptedly to both sides of the air purifier while the top airway allows the clean air to be spread to the common ward through the ceiling and surrounding walls. This creates a circulation airflow around the air purifier where the contaminant from the air is absorbed and filtered through the process. In addition, a weak clockwise vortex is observed in the space between the column and the patient bed. At the proximity of the air purifier, the airflow may be interfered by the air-conditioner diffuser and create an anti-clockwise vortex in front of the patient bed. It should be noted that the presence of short circuit flows at the air purifier may be due to the airway design.

\subsection{Transport of Aerosol Particles under the Influence of Air Purifier}

Fig. 10 shows the dispersion of the aerosol particles exhaled from the patient in the common ward for weak and medium exhalation at $15 \mathrm{~min}$ in an interval of $5 \mathrm{~s}$ under the influence of an air purifier.

As shown in Fig. 10(a) for weak exhalation, the particles concentrated at the front end of the common ward are reduced by $11.85 \%$ to about $54.19 \%$ compared to the common ward without an air purifier. The percentage of the total particles found in the ward with an air purifier is reduced by $11.73 \%$ compared to the common ward without an air purifier. Such a decrease in the number of particles could be explained by the introduction of an air purifier, the particles at the front and back end of the ward are being trapped by the air purifier. On the other hand, the simulation shows that more particles are found in the backend of the common ward when an air purifier is placed at the front end. The percentage of particle is increased from $33.96 \%$ to $45.81 \%$ 


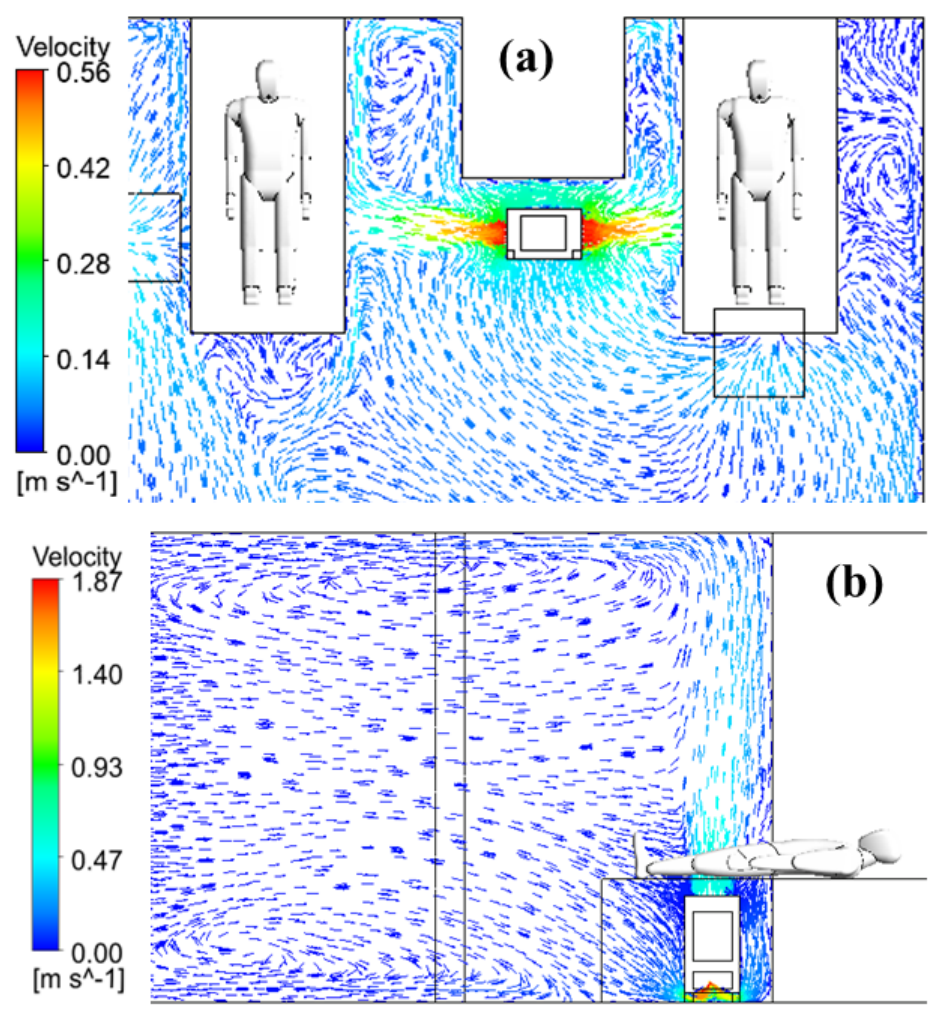

Fig. 9. Airflow distribution flow fields from the portable air purifier (a) Plan view. (b) Cross-section view.

for the common ward equipped with air purifier. This is because the outflow of the air purifier will introduce a positive pressure region and resist the particles flow to the front end of the common ward. Hence, the particles are prone to escape through the back end of the common ward, driven by the presence of exhaust fans. The opposite trend is also observed in the medium exhalation scenario, where the concentration of the particles at the front end of the common ward with an air purifier increase as much as $7.24 \%$ compared to the ward without an air purifier. The percentage of the total particles present in the ward with an air purifier increased by $24.99 \%$ due to two reasons. The first is the addition of the active airflow source induced by the air purifier, the second is explained by the higher velocity of the exhaled particle where it is less influenced by airflow.

In addition, the distribution of the particles at the height below $1.5 \mathrm{~m}$, within $1.5 \mathrm{~m}$ and $2.0 \mathrm{~m}$ and above $2.0 \mathrm{~m}$ for weak exhalation is about $68.78 \%, 11.04 \%$ and $20.18 \%$, respectively. Most of the particles stayed below $1.5 \mathrm{~m}$, above $2.0 \mathrm{~m}$, then followed by a human breathing zone. The total mass flow of the particles that flows out from the door, exhaust fans and air purifier for the weak exhalation are about $0.000297 \mathrm{~g} \mathrm{~s}^{-1}, 0.0853 \mathrm{~g} \mathrm{~s}^{-1}$ and $0.00862 \mathrm{~g} \mathrm{~s}^{-1}$, respectively. Around $85.33 \%$ of the particles flow out from the common ward through the exhaust fans and $8.62 \%$ of the particles are trapped by the air purifier. Only $0.3 \%$ of particles escaped the door and $5.75 \%$ of the particle remained in the room, whereas no particles escaped through the outlet of the air conditioner.

On the other hand, the distribution of the particles at the height below $1.5 \mathrm{~m}$, within $1.5 \mathrm{~m}$ and $2.0 \mathrm{~m}$ and above $2.0 \mathrm{~m}$ for medium exhalation is about $48.89 \%, 9.44 \%$ and $41.67 \%$, respectively. A similar trend is also observed for medium exhalation cases. The total mass flow of the particles flowing out from the door, exhaust fans and air purifier for the medium exhalation are approximately $0.0078 \mathrm{~g} \mathrm{~s}^{-1}, 0.387 \mathrm{~g} \mathrm{~s}^{-1}$ and $0.080 \mathrm{~g} \mathrm{~s}^{-1}$, respectively. About $77.37 \%$ of the particles will flow out from the exhaust fans and followed by the air purifier which is about $16.00 \%$, while the number of particles escaped from the door increase to $1.56 \%$ as compared to only $0.3 \%$ for the weak exhalation case. Besides, around $5.06 \%$ of the particles remained in the common ward and no particles escape through the outlet of the air conditioner. Although the efficiency of the air purifier for the medium exhalation case is about double that of the weak 

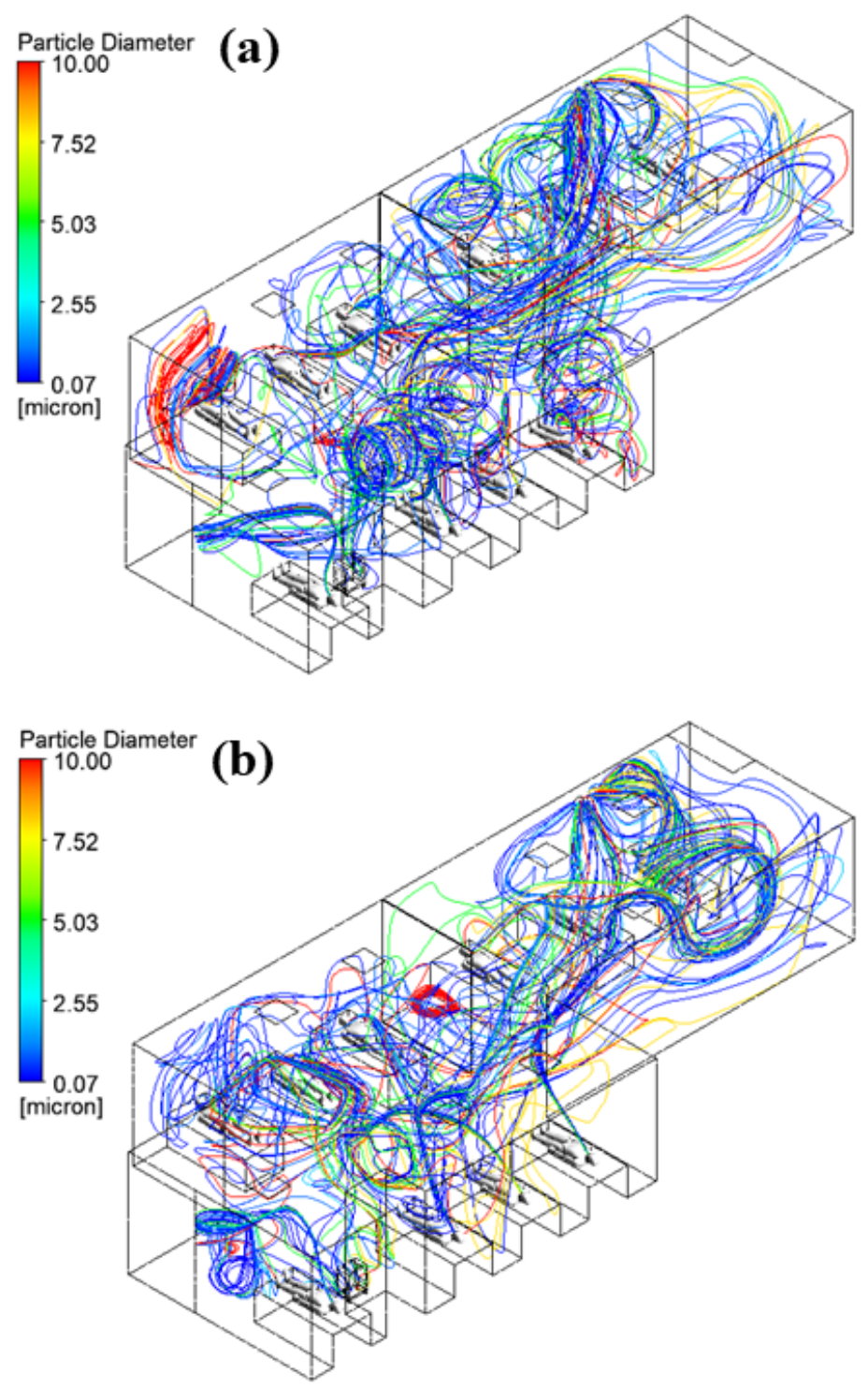

Fig. 10. Distribution of the exhaled particle under the influence of air purifier (a) weak exhalation. (b) medium exhalation.

exhalation case, the percentage of the particle escaped from the door is also increased. The overall efficiency of the air purifier is less than $20 \%$ as compared to exhaust fans and air conditioner outlets. Hence, this implies that the deployment of an air purifier in the common ward equipped with good ventilation is not sufficient to reduce the transmission risk of the virus-laden aerosol. Dispersion of the particles is heavily affected by the following factors: (1) airflow, (2) the presence of exhaust fan, (3) the airway suction and airway outlet from the air purifier, and (4) the intake and exhaust size and design of the air purifier. The deployment of an air purifier in the hospital ward does not warrant complete particle removal.

\subsection{Verification of the Collected Air Sample}

The average concentration of the $\mathrm{PM}_{2.5}$ recorded for 48 hours in the common ward without and with an air purifier is about $17.58 \pm 4.27 \mu \mathrm{g} \mathrm{m}^{-3}$ and $14.66 \mu \mathrm{g} \mathrm{m}^{-3}$ (Nor et al., 2021). The collected filter membranes from the low air volume sampler are processed and subjected to RT-qPCR to test the presence of the SARS-CoV-2 virus. The low volume sampler located far away from the air purifier shows a positive detection of the SARS-CoV-2 virus with a detection copy number of 10 \pm 7.44 copies $\mu \mathrm{L}^{-1}$ in the air sampler. However, the air sample near the air purifier did not show a positive result, probably due to the disturbance of the airflow induced by the air purifier and 
the low suction flow rate from the LVS. The experimental results agreed well with the simulation study. Hence, healthcare workers are still exposed to the risk of SARS-CoV-2 virus-laden aerosols even with air purifiers installed and well ventilation conditions. The size of particle dominates the diffusion of the particle. A large particle deposits faster, and the diffusion is slower, while a small particle diffuses faster under the influence of airflow and travel a great distance before depositing on the surface. Hence, face shields and face masks are indispensable equipment for health care workers treating the covid-19 patients.

\subsection{New Placement of the Air Purifiers}

The distribution of the aerosol particles in the common ward is also dependent on the number of air purifiers present in the common ward. Moreover, the effectiveness of the air purifier is depended on the location of the air purifier. Computational fluid dynamic results for the new placement of the air purifier at floor level and 1 meter above floor level are presented in Figs. 11 and 12 , respectively. Fig. 11 illustrates the streamline plot of the probable flow path for the exhaled particles released from the patient mouth for weak and medium exhalation under the influence of the air purifiers placed on the floor. On the other hand, Fig. 12 illustrates the streamline
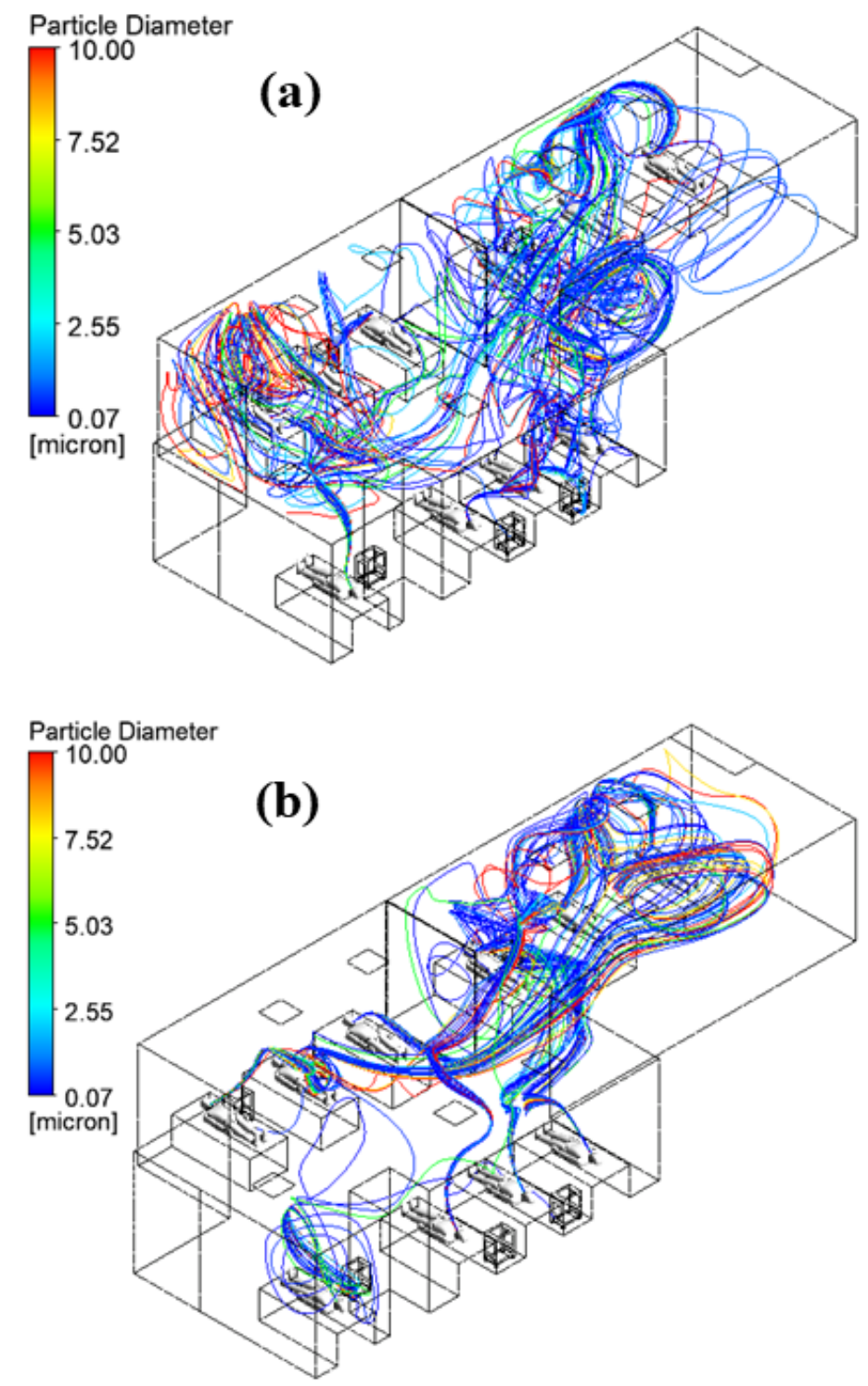

Fig. 11. Distribution of the exhaled particle under the influence of multiple air purifier at floor level (a) weak exhalation. (b) medium exhalation. 

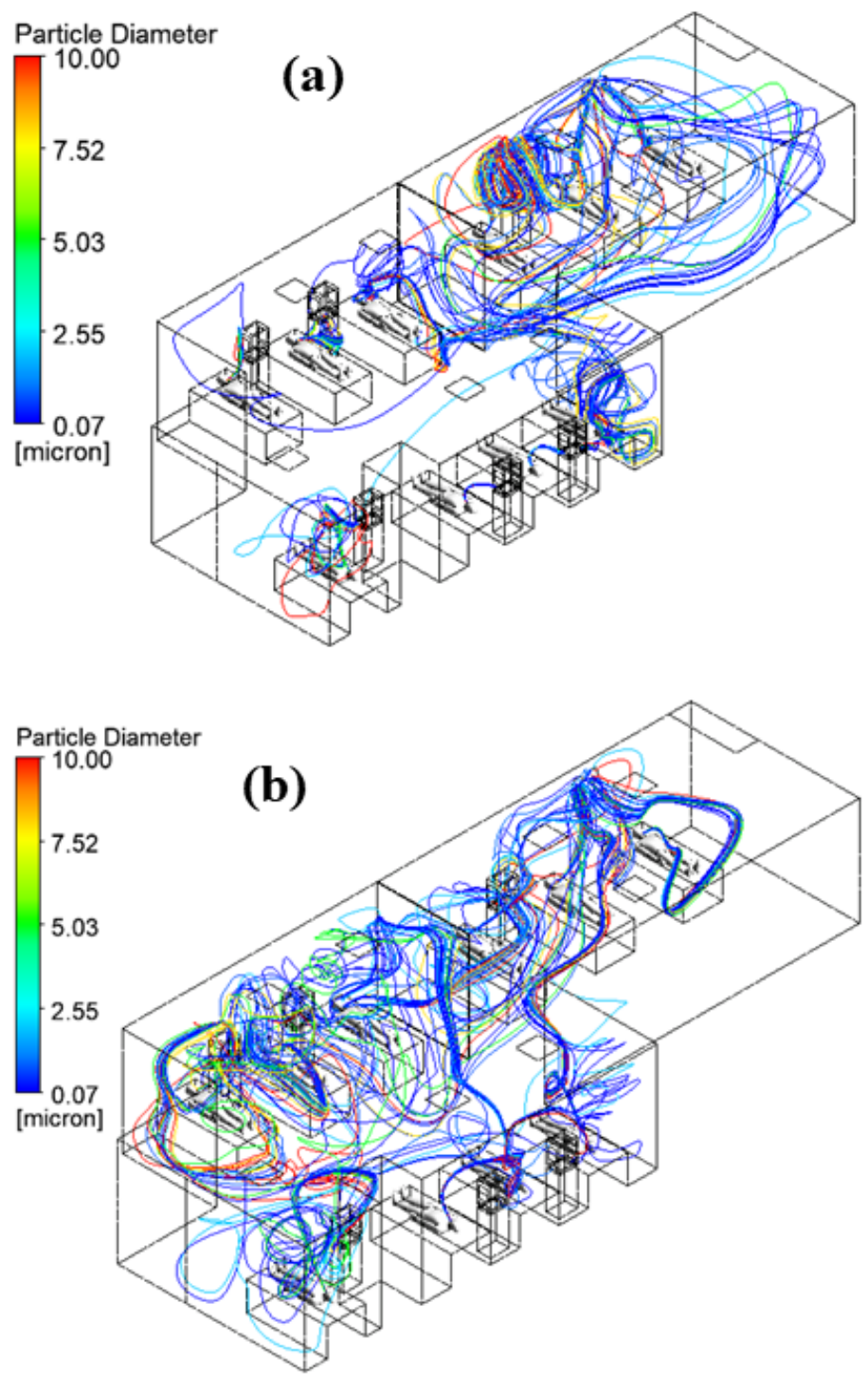

Fig. 12. Distribution of the exhaled particle under the influence of multiple air purifier at 1 meter above floor level (a) weak exhalation. (b) medium exhalation.

plot of the probable flow path for the exhaled particles released from the patient mouth for weak and medium exhalation under the influence of the air purifiers placed at 1 meter above floor level. The air purifier is placed next to the patient to optimize the evacuation of the aerosol when it is exhaled out from the patient's mouth.

The percentage of the exhaled particles vented through the exhaust fan, outlet and air purifiers are shown in Table 3. No particles flew out from the door for the new placement of the air purifier which is at floor level or $1 \mathrm{~m}$ height. The efficiency of the air purifier increased when multiple air purifier is deployed and placed near to the patient. Besides, it is also observed that the efficiency of the air purifier is increased when it was placed at $1 \mathrm{~m}$ above the floor level as compared to the air purifier placed at floor level. For weak exhalation case, the total efficiency of the air purifier is increased from $37.14 \%$ to $59.91 \%$. For medium exhalation case, the total efficiency of the air purifier is increased from $36.44 \%$ to $48.81 \%$. The factors that contribute to this phenomenon is influenced by the design of the air purifier and the position of the air purifier. The current air purifier has small intakes at the bottom part and a large clean air outlet at the top part which reduce the overall efficiency of the air purifier in capturing the exhaled particles when placed at the floor level. In addition, the particles are small in size, and take a longer time to reach the air purifier placed on the floor level compared to the air purifier placed 1 meter above the floor level 
Table 3. Distribution of the aerosol particles vented out from different devices.

\begin{tabular}{llllll}
\hline \multirow{2}{*}{ Location } & \multicolumn{2}{c}{ Air purifier on floor level } & & \multicolumn{2}{c}{ Air purifier at 1 meter above floor } \\
\cline { 2 - 3 } \cline { 5 - 6 } & Weak exhalation & Medium exhalation & & Weak exhalation & Medium exhalation \\
\hline Exhaust fans and outlet & $54.13 \%$ & $59.29 \%$ & $37.86 \%$ & $46.23 \%$ \\
Door opening & $0.00 \%$ & $0.00 \%$ & $0.00 \%$ & $0.00 \%$ \\
Air purifier A & $0.00 \%$ & $6.06 \%$ & $9.41 \%$ & $4.07 \%$ \\
Air purifier B & $0.91 \%$ & $0.07 \%$ & $10.00 \%$ & $6.00 \%$ \\
Air purifier C & $3.48 \%$ & $0.15 \%$ & $13.90 \%$ & $3.50 \%$ \\
Air purifier D & $6.85 \%$ & $1.01 \%$ & $9.98 \%$ & $15.06 \%$ \\
Air purifier E & $15.64 \%$ & $6.10 \%$ & $9.88 \%$ & $4.47 \%$ \\
Air purifier F & $10.25 \%$ & $23.05 \%$ & $6.73 \%$ & $15.72 \%$ \\
\hline
\end{tabular}

and near to the patient. The exhaled particles from the patient mouth will be attracted by the immediate suction from the air purifier. However, the effect of suction from two exhaust fans is more prominent compared to suction from the six air purifiers. There are no exhaled particles being captured by the air purifier $A$, probably due to the lower position of the air purifier and the distal location from the aerosol generation source. For weak exhalation case, since air purifier Bis located below the air conditioner diffusers, the interaction between the diffuser and air purifier is likely to create a complex airflow and reduces the overall efficiency of the air purifier when placed at the floor level. However, the efficiency of the air purifier B can be increased by elevating the air purifier by $1 \mathrm{~m}$ and near the aerosol generation source.

For a single air purifier, the total particles from the weak exhalation vented out from the common ward are about $94.25 \%$. For the air purifiers placed on the floor and 1 meter above the floor level, the total particles from the weak exhalation vented out from the common ward are about $91.26 \%$ and $97.77 \%$, respectively. However, the total efficiency of the air purifier for weak exhalation increases from $8.62 \%$ to $37.14 \%$ and $59.91 \%$ from the single air purifier to multiple air purifiers placed on the floor and 1 meter above the floor level, respectively. Conversely, for a single air purifier, the particles from the medium exhalation vented out from the common ward are about $94.94 \%$. For the air purifiers placed on the floor and 1 meter height, the particles from the medium exhalation vented out from the common ward are about $95.73 \%$ and $95.04 \%$, respectively. The total efficiency of the air purifier for medium exhalation increases from $16 \%$ to $36.44 \%$ and $48.81 \%$ from a single air purifier to multiple air purifiers placed on the floor and 1 meter above the floor level, respectively. The reduction of the particles vented out from the exhaust fans is contributed by the increased particles absorbed by air purifiers. It can be concluded that the location of the air purifier is an important factor to reduce the dispersion of exhaled particles in the open ward, hence, reducing nosocomial transmission through inhalation. However, the air purifier is not as effective when compared to an aerosol arrestor proposed in our previous study (Saw et al., 2021). Hence, it is advisable that the healthcare workers must wear the face mask and face shield when dealing with the SARS-CoV-2 patients to reduce the risk of transmission through inhalation and deposition.

\section{CONCLUSIONS}

In conclusion, the computational fluid dynamic analysis showed that more particles are concentrated at the front end of the common ward and escape the room through the door opening and exhaust fans. Most of the particles are expected to stay below $1.5 \mathrm{~m}$ under the influence of air conditioner airflow. The use of a single air purifier only has a minimum impact in reducing the dispersion of the particles. Approximately $16 \%$ of the particles will be trapped in the air purifier in medium exhalation scenario whereas $8.62 \%$ of the particles trapped in the air purifier in weak exhalation scenario. Besides, the air sampling in the common ward located further away from the air purifier shows positive SARS-CoV-2. On the other hand, the air sampling located near the air purifier showed SARS-CoV-2 negative. This is probably due to the low suction volume of the air sampler with only $0.3 \mathrm{CMH}$ and the high flow rate of the air purifier which is about $700 \mathrm{CMH}$ that disturbs the air sampler in capturing the virus particle. The negative results of the RT-qPCR 
test on the sample next to the air purifier do not imply that the air purifier effectively suppresses the transmission of the SARS-CoV-2 virus particle.

Location of the air purifier and ventilation level of the room should be considered to yield better performance. When comparing the effects of air purifier numbers and installation height, multiple air purifiers placed at 1 meter above the floor can increase the efficiency from $37.14 \%$ to $59.91 \%$ for weak exhalation and from $36.44 \%$ to $48.81 \%$ for medium exhalation. The aerosol particles that flew out from the door is reduced completely by employing multiple air purifiers in the common ward. In addition, compared with the multiple air purifiers placed on the floor level and multiple air purifiers placed at 1 meter above the floor level, it is clearly shown that the efficiency of the air purifier at 1 meter height and placed closer to the aerosol generation source is increased. Installation of multiple air purifiers increases the total efficiency. However, the efficiency of the individual air purifier is still less than $25 \%$. Besides, it should be highlighted that the efficiency of the HEPA filter of the air purifier needs further investigation. The simulation works show that using air purifier alone is not sufficient to reduce the dispersion of the aerosol particles in the hospital ward and it is recommended that the uses of a face shield and face mask are necessary to minimize nosocomial transmission in the hospital.

\section{NOMENCLATURE}

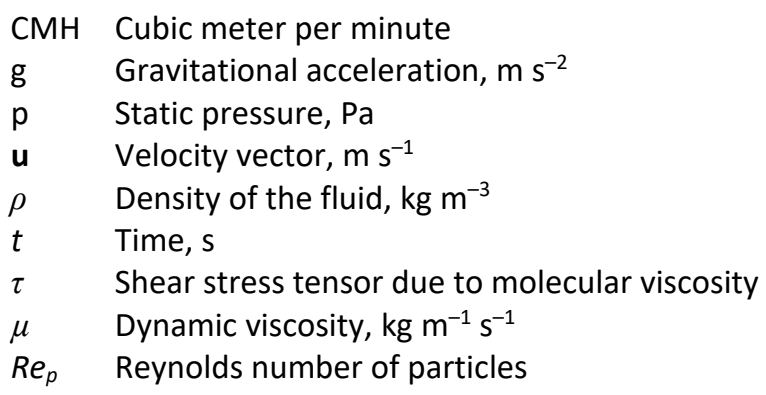

\section{ACKNOWLEDGEMENTS}

We would like to thank the COVID-19 hospital in Kuala Lumpur for allowing us to perform air sampling in the executive ward during the national lockdown period. The study is supported by Universiti Kebangsaan Malaysia research grant with grant number (COVID-2020-002), Universiti Malaya COVID-19 Special Research Grant with grant number (CSRG009-2020ST) and Universiti Tunku Abdul Rahman research grant with grant number (6251/B02). In addition, we would like to thank the healthcare workers at the hospital that work and assist us to collect the samples. Nevertheless, we would like to pay our gratitude to Malaysia and worldwide healthcare workers that work relentlessly to take care of the patient and combat the spreading of SARS-CoV- 2 .

\section{REFERENCES}

Ahlawat, A., Wiedensohler, A., Mishra, S.K. (2020). An overview on the role of relative humidity in airborne transmission of SARS-CoV-2 in indoor environments. Aerosol Air Qual. Res. 20, 1856-1861. https://doi.org/10.4209/aaqr.2020.06.0302

Almilaji, O. (2021). Air recirculation role in the spread of COVID-19 onboard the diamond princess cruise ship during a quarantine period. Aerosol Air Qual. Res. 21, 200495. https://doi.org/10.4 209/aaqr.200495

Ansaripour, M., Abdolzadeh, M., Sargazizadeh, S. (2016). Computational modeling of particle transport and distribution emitted from a Laserjet printer in a ventilated room with different ventilation configurations. Appl. Therm. Eng. 103, 920-933. https://doi.org/10.1016/j.applthe rmaleng.2016.04.137

Ashgriz, N., Mostaghimi, J. (2002). An introduction to computational fluid dynamics, in: Saleh, J.M. (Ed.), Fluid flow handbook. Vol. 1, McGraw-Hill Education, Canada, pp. 1-49. 
Atkinson, J., Chartier, Y., Pessoa-Silva, C.L., Jensen, P., Li, Y., Seto, W.H. (2009). Natural Ventilation for Infection Control in Health-Care Settings. https://www.who.int/water_sanitation_health/p ublications/natural_ventilation.pdf (accessed 20 December 2021).

Bergam, N., Chen, L., Lende, S., Snow, S., Zhang, J., DiBuono, M.J., Calzaretto, N.J. (2020). Designing and Simulating a Smart SARS-CoV-2 Air Purifier. https://soe.rutgers.edu/sites/defa ult/files/imce/pdfs/GSET_2020__Designing\%20and\%20Simulating\%20a\%20Smart\%20SARSCoV-2\%20\%20Air\%20Purifier.pdf (accessed 20 December 2021).

Bhattacharyya, S., Dey, K., Paul, A.R., Biswas, R. (2020). A novel CFD analysis to minimize the spread of COVID-19 virus in hospital isolation room. Chaos. Solitons. Fractals. 139, 110294. https://doi.org/10.1016/j.chaos.2020.110294

Borro, L., Mazzei, L., Raponi, M., Piscitelli, P., Miani, A., Secinaro, A. (2021). The role of air conditioning in the diffusion of Sars-CoV-2 in indoor environments: A first computational fluid dynamic model, based on investigations performed at the Vatican State Children's hospital. Environ. Res. 193, 110343. https://doi.org/10.1016/j.envres.2020.110343

Bourouiba, L. (2020). Turbulent gas clouds and respiratory pathogen emissions: Potential implications for reducing transmission of COVID-19. JAMA 323, 1837-1838. https://doi.org/ 10.1001/jama.2020.4756

Burgmann, S., Janoske, U. (2021). Transmission and reduction of aerosols in classrooms using air purifier systems. Phys. Fluids. 33, 033321. https://doi.org/10.1063/5.0044046

Chao, C.Y.H., Wan, M.P., Morawska, L., Johnson, G.R., Ristovski, Z.D., Hargreaves, M., Mengersen, K., Corbett, S., Li, Y., Xie, X., Katoshevski, D. (2009). Characterization of expiration air jets and droplet size distributions immediately at the mouth opening. J. Aerosol. Sci. 40, 122-133. https://doi.org/10.1016/j.jaerosci.2008.10.003

Chia, P.Y., Coleman, K.K., Tan, Y.K., Ong, S.W.X., Gum, M., Lau, S.K., Lim, X.F., Lim, A.S., Sutjipto, S., Lee, P.H., Son, T.T., Young, B.E., Milton, D.K., Gray, G.C., Schuster, S., Barkham, T., De, P.P., Vasoo, S., Chan, M., Ang, B.S.P., et al. (2020). Detection of air and surface contamination by SARS-CoV-2 in hospital rooms of infected patients. Nat. Commun. 11, 2800. https://doi.org/10. 1038/s41467-020-16670-2

Cooper, E., Wang, Y., Stamp, S., Burman, E., Mumovic, D. (2021). Use of portable air purifiers in homes: Operating behaviour, effect on indoor $\mathrm{PM}_{2.5}$ and perceived indoor air quality. Build. Environ. 191, 107621. https://doi.org/10.1016/j.buildenv.2021.107621

Curtius, J., Granzin, M., Schrod, J. (2020). Testing mobile air purifiers in a school classroom: Reducing the airborne transmission risk for SARS-CoV-2. Aerosol. Sci. Technol. 55, 586-599. https://doi.org/10.1080/02786826.2021.1877257

Dong, E., Du, H., Gardner, L. (2020). An interactive web-based dashboard to track COVID-19 in real time. Lancet Infect. Dis. 20, 533-534. https://doi.org/10.1016/S1473-3099(20)30120-1

Edwards, D.A., Man, J.C., Brand, P., Katstra, J.P., Sommerer, K., Stone, H.A., Nardell, E., Scheuch, G. (2004). Inhaling to mitigate exhaled bioaerosols. Proc. Natl. Acad. Sci. USA 101, 1738317388. https://doi.org/10.1073/pnas.0408159101

Elias, B., Bar-Yam, Y. (2020). Could air filtration reduce COVID-19 severity and spread. https://necsi.edu/could-air-filtration-reduce-covid19-severity-and-spread (accessed 20 December 2021).

Fabian, P., Brain, J., Houseman, E.A., Gern, J., Milton, D.K. (2011). Origin of exhaled breath particles from healthy and human rhinovirus-infected subjects. J. Aerosol. Med. Pulm. Drug. Deliv. 24, 137-147. https://doi.org/10.1089/jamp.2010.0815

Fears, A.C., Klimstra, W.B., Duprex, P., Hartman, A., Weaver, S.C., Plante, K.S., Mirchandani, D., Plante, J.A., Aguilar, P.V., Fernández, D., Nalca, A., Totura, A., Dyer, D., Kearney, B., Lackemeyer, M., Bohannon, J.K., Johnson, R., Garry, R.F., Reed, D.S., Roy, C.J. (2020). Persistence of severe acute respiratory syndrome coronavirus 2 in aerosol suspensions. Emerging Infect. Dis. 26, 2168-2171. https://doi.org/10.3201/eid2609.201806

Feng, G., Bi, Y., Zhang, Y., Cai, Y., Huang, K. (2020). Study on the motion law of aerosols produced by human respiration under the action of thermal plume of different intensities. Sustain. Cities Soc. 54, 101935. https://doi.org/10.1016/j.scs.2019.101935

Gorbunov, B. (2021). Aerosol particles generated by coughing and sneezing of a SARS-CoV-2 (COVID-19) host travel over 30 m distance. Aerosol Air Qual. Res. 21, 200468. https://doi.org/ 10.4209/aaqr.200468 
Huang, P., Bardina, J., Coakley, T. (1997). Turbulence modeling validation, testing, and development. NASA technical memorandum 110446.

Jones, N.R., Qureshi, Z.U., Temple, R.J., Larwood, J.P.J., Greenhalgh, T., Bourouiba, L. (2020). Two metres or one: What is the evidence for physical distancing in covid-19? BMJ 370, m3223. https://doi.org/10.1136/bmj.m3223

Kim, J.M., Chung, Y.S., Jo, H.J., Lee, N.J., Kim, M.S., Woo, S.H., Park, S., Kim, J.W., Kim, H.M., Han, M.G. (2020). Identification of coronavirus isolated from a patient in Korea with COVID-19. Osong. Public. Health. Res. Perspect. 11, 3-7. https://doi.org/10.24171/j.phrp.2020.11.1.02

Kwon, S.B., Park, J., Jang, J., Cho, Y., Park, D.S., Kim, C., Bae, G.N., Jang, A. (2012). Study on the initial velocity distribution of exhaled air from coughing and speaking. Chemosphere 87, 12601264. https://doi.org/10.1016/j.chemosphere.2012.01.032

Lee, B.U. (2022). Airborne transmission of the SARS-CoV-2 Delta variant and the SARS-CoV-2 Omicron variant. Aerosol Air Qual. Res. 22, 210250. https://doi.org/10.4209/aaqr.210250

Lee, G.G., Allan, W.D.E., Goni Boulama, K. (2013). Flow and performance characteristics of an Allison 250 gas turbine S-shaped diffuser: Effects of geometry variations. Int. J. Heat. Fluid. Flow. 42, 151-163. https://doi.org/10.1016/j.ijheatfluidflow.2013.02.004

Li, Y., Qian, H., Hang, J., Chen, X., Hong, L., Liang, P., Li, J., Xiao, S., Wei, J., Liu, L., Kang, M. (2020). Evidence for probable aerosol transmission of SARS-CoV-2 in a poorly ventilated restaurant. Build. Environ. 196, 107788. https://doi.org/10.1016/j.buildenv.2021.107788

Licina, D., Pantelic, J., Melikov, A., Sekhar, C., Tham, K.W. (2014). Experimental investigation of the human convective boundary layer in a quiescent indoor environment. Build. Environ. 75, 79-91. https://doi.org/10.1016/j.buildenv.2014.01.016

Liu, Y., Ning, Z. (2020). Aerodynamic analysis of SARS-CoV-2 in two Wuhan hospitals. Nature 582, 557-560. https://doi.org/10.1038/s41586-020-2271-3

Liu, Y., Zhou, B., Wang, J., Zhao, B. (2021). Health benefits and cost of using air purifiers to reduce exposure to ambient fine particulate pollution in China. J. Hazard. Mater. 414, 125540. https://doi.org/10.1016/j.jhazmat.2021.125540

Marzec, Ł., Buliński, Z., Krysiński, T. (2021). Fluid structure interaction analysis of the operating Savonius wind turbine. Renewable Energy 164, 272-284. https://doi.org/10.1016/j.renene.20 20.08.145

McNamara, M.L., Thornburg, J., Semmens, E.O., Ward, T.J., Noonan, C.W. (2017). Reducing indoor air pollutants with air filtration units in wood stove homes. Sci. Total. Environ. 592, 488494. https://doi.org/10.1016/j.scitotenv.2017.03.111

Melikov, A.K. (2015). Human body micro-environment: The benefits of controlling airflow interaction. Build. Environ. 91, 70-77. https://doi.org/10.1016/j.buildenv.2015.04.010

Menter, F.R., Kuntz, M., Langtry, R. (2003). Ten years of industrial experience with the SST turbulence model, in: Hanjalic, K., Nagano, Y., Tummers, M. (Eds.), Turbulence Heat and mass transfer, Vol. 4, Begell House, Inc., Connecticut, pp. 625-632.

Nor, N.S.M., Yip, C.W., Ibrahim, N., Jaafar, M.H., Rashid, Z.Z., Mustafa, N., Hamid, H.H.A., Chandru, K., Latif, M.T., Saw, P.E., Lin, C.Y., Alhasa, K.M., Hashim, J.H., Nadzir, M.S.M. (2021). Particulate matter $\left(\mathrm{PM}_{2.5}\right)$ as a potential SARS-CoV-2 carrier. Sci. Rep. 11, 2508. https://doi.org/ 10.1038/s41598-021-81935-9

Novoselac, A., Siegel, J.A. (2009). Impact of placement of portable air cleaning devices in multizone residential environments. Build. Environ. 44, 2348-2356. https://doi.org/10.1016/ j.buildenv.2009.03.023

Papineni, R.S., Rosenthal, F.S. (1997). The size distribution of droplets in the exhaled breath of healthy human subjects. J. Aerosol. Med. 10, 105-116. https://doi.org/10.1089/jam.1997.10. 105

Raghava, N., Vidovic, B. (2020). Using computational fluid dynamics to evaluate the role of air purification in reducing fallow time in dentistry. Int. J. Dent. Oral. Health. 7, 1-11. https://doi.org/10.16966/2378-7090.362

Ren, J., Wang, Y., Liu, Q., Liu, Y. (2021). Numerical study of three ventilation strategies in a prefabricated COVID-19 inpatient ward. Build. Environ. 188, 107467. https://doi.org/10.10 16/j.buildenv.2020.107467

Riediker, M., Monn, C. (2021). Simulation of SARS-CoV-2 aerosol emissions in the infected population and resulting airborne exposures in different indoor scenarios. Aerosol Air Qual. 
Res. 21, 200531. https://doi.org/10.4209/aaqr.2020.08.0531

Saw, L.H., Poon, H.M., Thiam, H.S., Cai, Z., Chong, W.T., Pambudi, N.A., King, Y.J. (2018). Novel thermal management system using mist cooling for lithium-ion battery packs. Appl. Energy 223, 146-158. https://doi.org/10.1016/j.apenergy.2018.04.042

Saw, L.H., Leo, B.F., Norefrina, S.M.N., Chee, W.Y., Nazlina, I., Haris, H.A.H., Mohd, T.L., Chin, Y.L., Mohd, S.M.N. (2021). Modeling aerosol transmission of SARS-CoV-2 from human exhaled particles in a hospital ward. Environ. Sci. Pollut. Res. 28, 53478-53492. https://doi.org/10.1 007/s11356-021-14519-9

Shao, D., Du, Y., Liu, S., Brunekreef, B., Meliefste, K., Zhao, Q., Chen, J., Song, X., Wang, M., Wang, J., Xu, H., Wu, R., Wang, T., Feng, B., Lung, C. S., Wang, X., He, B., Huang, W. (2017). Cardiorespiratory responses of air filtration: $A$ randomized crossover intervention trial in seniors living in Beijing: Beijing Indoor Air Purifier StudY, BIAPSY. Sci. Total Environ. 603-604, 541-549. https://doi.org/10.1016/j.scitotenv.2017.06.095

Sharma, A., Tiwari, S., Deb, M.K., Marty, J L. (2020). Severe acute respiratory syndrome coronavirus-2 (SARS-CoV-2): A global pandemic and treatment strategies. Int. J. Antimicrob. Agents. 56, 106054. https://doi.org/10.1016/j.ijantimicag.2020.106054

Shaughnessy, R.J., Sextro, R.G. (2006). What is an effective portable air cleaning device? A review. J. Occup. Environ. Hyg. 3, 169-81. https://doi.org/10.1080/15459620600580129

Shereen, M. A., Khan, S., Kazmi, A., Bashir, N., Siddique, R. (2020). COVID-19 infection: Emergence, transmission, and characteristics of human coronaviruses. J. Adv. Res. 24, 91-98. https://doi.org/10.1016/j.jare.2020.03.005

Sparrow, E.M., Abraham, J.P., Minkowycz, W.J. (2009). Flow separation in a diverging conical duct: Effect of Reynolds number and divergence angle. Int. J. Heat. Mass. Transf. 52, 30793083. https://doi.org/10.1016/j.ijheatmasstransfer.2009.02.010

Sun, S., Li, J., Han, J. (2021). How human thermal plume influences near-human transport of respiratory droplets and airborne particles: A review. Environ Chem Lett. 19, 1971-1982. https://doi.org/10.1007/s10311-020-01178-4

Tang, J.W., Nicolle, A.D., Klettner, C.A., Pantelic, J., Wang, L., Suhaimi, A.B., Tan, A.Y.L., Ong, G.W.X., Su, R., Sekhar, C., Cheong, D.D.W., Tham, K.W. (2013). Airflow dynamics of human jets: Sneezing and breathing - potential sources of infectious aerosols. PLoS One 8, e59970. https://doi.org/10.1371/journal.pone.0059970

Tellier, R., Li, Y., Cowling, B.J., Tang, J.W. (2020). Recognition of aerosol transmission of infectious agents: A commentary. BMC. Infect. Dis. 19, 101. https://doi.org/10.1186/s12879-019-3707-y

van Doremalen, N., Bushmaker, T., Morris, D.H., Holbrook, M.G., Gamble, A., Williamson, B.N. Tamin, A., Harcourt, J.L., Thornburg, N.J., Gerber, S.I., Lloyd-Smith, J.O., de Wit, E., Munster, V.J. (2020). Aerosol and surface stability of SARS-CoV-2 as compared with SARS-CoV-1. N. Engl. J. Med. 382, 1564-1567. https://doi.org/10.1056/NEJMc2004973

Vianello, A., Jensen, R.L., Liu, L., Vollertsen, J. (2019). Simulating human exposure to indoor airborne microplastics using a Breathing Thermal Manikin. Sci. Rep. 9, 8670. https://doi.org/10.1038/ s41598-019-45054-w

Vuorinen, V., Aarnio, M., Alava, M., Alopaeus, V., Atanasova, N., Auvinen, M., Balasubramanian, N., Bordbar, H., Erästö, P., Grande, R., Hayward, N., Hellsten, A., Hostikka, S., Hokkanen, J., Kaario, O., Karvinen, A., Kivistö, I., Korhonen, M., Kosonen, R., Kuusela, J., et al. (2020). Modelling aerosol transport and virus exposure with numerical simulations in relation to SARS-CoV-2 transmission by inhalation indoors. Saf. Sci. 130, 104866. https://doi.org/10.1016/j.ssci.202 0.104866

Xie, X., Li, Y., Sun, H., Liu, L. (2009). Exhaled droplets due to talking and coughing. J. R. Soc. Interface 6, S703-S714. https://doi.org/10.1098/rsif.2009.0388.focus

Yang, S., Lee, G.W., Chen, C.M., Wu, C.C., Yu, K.P. (2007). The size and concentration of droplets generated by coughing in human subjects. J. Aerosol. Med. 20, 484-494. https://doi.org/ 10.1089/jam.2007.0610

Yang, X., Ou, C., Yang, H., Liu, L., Song, T., Kang, M., Lin, H., Hang, J. (2020). Transmission of pathogen-laden expiratory droplets in a coach bus. J. Hazard. Mater. 397, 122609-122609. https://doi.org/10.1016/j.jhazmat.2020.122609

Zhao, B., Liu, Y., Chen, C. (2020). Air purifiers: A supplementary measure to remove airborne SARS-CoV-2. Build. Environ. 177, 106918. https://doi.org/10.1016/j.buildenv.2020.106918 
Zhu, S., Kato, S., Yang, J. H. (2006). Study on transport characteristics of saliva droplets produced by coughing in a calm indoor environment. Build. Environ. 41, 1691-1702. https://doi.org/ 10.1016/j.buildenv.2005.06.024 